Research Article

\title{
Pricing Strategies of Multichannel Apparel Supply Chain Based on Showrooming and Information Sharing
}

\author{
Shanshan Wang $\mathbb{D}^{1}$ Tian Luo $\mathbb{D}^{2}{ }^{2}$ and Daofang Chang ${ }^{1}$ \\ ${ }^{1}$ Institute of Logistics Science and Engineering, Shanghai Maritime University, 201306 Shanghai, China \\ ${ }^{2}$ School of Economics \& Management, Shanghai Maritime University, 201306 Shanghai, China \\ Correspondence should be addressed to Tian Luo; 201830510048@stu.shmtu.edu.cn
}

Received 8 November 2020; Revised 14 March 2021; Accepted 26 March 2021; Published 17 April 2021

Academic Editor: Mariusz Michta

Copyright ( $) 2021$ Shanshan Wang et al. This is an open access article distributed under the Creative Commons Attribution License, which permits unrestricted use, distribution, and reproduction in any medium, provided the original work is properly cited.

\begin{abstract}
This paper examines the influence of information forecast accuracy on the profits of the supply chain under the circumstance of a multichannel apparel supply chain. Due to the emergence of multichannel, customer showrooming behavior is becoming increasingly prevalent. For example, consumers usually buy garments online after experiencing the service in the traditional bricks and mortar in the clothing industry. Meanwhile, there are often information barriers between the manufacturer and the retailer, which will affect enterprise decision-making. To solve these problems, this paper mainly investigates the information sharing and customer showrooming phenomenon, which includes four models: no information sharing without showrooming model (NN), information sharing without showrooming model (SN), no information sharing with showrooming model (NS), and information sharing with showrooming model (SS). The numerical analysis shows that under the impact of the forecast error, information sharing between channel members is more favorable than no information sharing when parameters satisfy certain conditions. From the perspectives of the retailer, the manufacturer, and the whole supply chain, customer showrooming behavior will bring them less profit. These conclusions mean that the retailer should share information with the manufacturer and adjust their service level and sales price to alleviate the effect of showrooming.
\end{abstract}

\section{Introduction}

To quickly occupy the market and enhance the brand popularity, multichannels are established in the terminal market of the apparel industry $[1,2]$. In the past, the main sales channels were traditional offline retail channels, such as wholesale markets, shopping malls, and supermarkets. Nowadays, with the rapid development of the Internet and the change of customers' lifestyle, customers prefer shopping in the online channel, which mainly includes Amazon, Taobao, WeChat, and livestreaming platforms $[3,4]$. Though the e-commerce industry is growing quickly, certain consumers still choose to go to large-scale department stores to buy clothes that fit them well, especially for some mediumand high-grade garments. To maximize their utility, a part of customers will choose to buy clothes immediately after fitting them in physical stores, some customers will place orders directly online, and the rest will try on clothes in physical stores and then transfer to buy clothes at lower prices via mobile phones or computers. This shopping behavior shift from offline to online is called customer showrooming behavior [5-8].

From a single marketing channel of offline physical stores to the current widespread multichannel combination of offline physical stores and online direct stores, different individuals in the multichannel tend to form an information island for their own benefit, which will aggravate the channel contradiction. Meanwhile, differentiated information received by different decision-makers will affect the final pricing strategies. If the channel information of the manufacturer and the retailer is isolated from each other, the retailer will not be able to transmit accurate information to the manufacturer, which will fail to manage customer needs in a unified manner. As mentioned in [9], information 
sharing improves the quality of fast fashion supply chain decision-making and plays an important role in improving supply chain performance. Moreover, the literature [9] also shows that information sharing can reduce inventory backlog and replenish inventory timely, which is conducive to the entire supply chain and ultimately alleviates multichannel conflicts.

We consider the two-stage supply chain composed of a manufacturer and a retailer. On the one hand, the manufacturer directly faces customers through the network direct marketing channel. On the other hand, the manufacturer sells clothes through its subordinate retailer. To lighten the loss caused by showrooming, in addition to regular physical stores, the retailer sets up a new channel named WeChat to attract customers by releasing information about the latest costumes through WeChat moments [10]. In the multichannel fashion supply chain, we establish the uncertain demand functions and profit functions for retailer physical store, retailer's WeChat, and manufacturer's Internet direct channel with or without showrooming and information sharing. Next, we use the Bayesian Stackelberg game to obtain the equilibrium solutions of no information sharing without showrooming model $(\mathrm{NN})$, information sharing without showrooming model (SN), no information sharing with showrooming model (NS), and information sharing with showrooming model (SS) and analyze the impact of the forecast error on profits in above four models.

In the apparel supply chain, some researchers investigated the problem of demand disruption among multichannels, which mainly focused on inventory overstock and stockout, or cannibalizing goods among different channels $[11,12]$. Compared with the past, firstly, the change of clothing demand in this paper is linked to the seasons. The prediction error increases with the garment demand in summer and winter, and the trend of the error with season conforms to the normal distribution curve. Therefore, this paper decides to establish an uncertain demand function with prediction error obeying normal distribution. Secondly, the increase in the number of clothing terminal sales channels, the convenience of service, and the rapid development of the network reduce the cost of obtaining commodity information, so the cross-channel showrooming behavior of customers is becoming more widespread. Research studies on customer showrooming involve a wide range of fields, such as the mobile phone industry [13], the film industry [6], and the hotel industry [14], but generally only involve dual-channel, and there are few papers about the apparel industry under multichannel. Nevertheless, we study channel pricing strategies under the showrooming, but also the situation without showrooming. Furthermore, the combination of information sharing with or without showrooming is rarely seen in other papers.

The rest of this paper is arranged as follows. In Section 2, we review the related work. Section 3 describes these problems and introduces the model. In Section 4, we use the Bayesian Stackelberg game to find the expected equilibrium solutions without showrooming. Section 5 is similar to Section 4, but Section 5 focuses on showrooming. Section 6 analyzes and compares the impact of prediction accuracy on the profit of each channel in the four models. Section 7 shows the conclusions, managerial implications, and the areas that need to be further explored in the future. All proofs are provided in the Appendix.

\section{Literature Review}

In this paper, there are three streams of the multichannel apparel supply chain pricing: game theory, customer showrooming behavior, and the information sharing among channel members.

2.1. Game Theory in Supply Chain. In this paper, we use the Bayesian Stackelberg game to get the equilibrium solutions with incomplete information and draw the relevant conclusions through the comparison and analysis of different models, which is rarely mentioned in other papers. Shib [15] studied a newsboy inventory model to analyze the price competition between green marketing and nongreen marketing under government subsidies and taxes. The results showed that the managers should pay attention to the development of green products when the government gave high subsidies and low tariffs to green products. Shib [16] proposed the game theory method of calculus to study the price and quality decisions of products. He studied the pricing of green products under the centralized model and the decentralized model in the monopolistic market and the price competition between conventional products and green products. This paper concluded that the benefits under the integration model were higher than those under the decentralization model. Compared with conventional products, green products can occupy the market with an acceptable price and product quality. Shib [17] proposed an analytical game theory method to determine the optimal order quantity, reorder point, and sales teams' initiatives in the production-inventory two-stage models. Nikunja et al. [18] believed that in the context of the Stackelberg game, this paper considered three possible recycling activities of waste products, namely, retailer-led recycling, manufacturer-led recycling, and third-party-led recycling. It was found that the third party's participation in waste product recycling activities was often disadvantageous. Arpita et al. [5] established a single-period newsboy model, then used Stackelberg, Bertrand, Cournot Bertrand, and integrated methods to analyze and compare the profits of a manufacturer and two competing retailers. Izabela et al. [19] compared the profit of each member under the incentive policy and the nonincentive policy considering the twoperiod and double-period game structure. The results showed that in the two-stage procurement decision of the manufacturer's Stackelberg game, the manufacturer has obtained a higher profit, and the level of greening has always been at a higher level. In the retailer's single-cycle purchasing decision under the Stackelberg game, the retailer's greening level and profit were the highest. Moumita et al. [20] put forward the mathematical model of the green product inventory system in the green manufacturing industry. Then, they established the profit functions of 
continuous known distribution, discrete distribution, and distribution-free case. The results showed that green technology, facility investment, and service level were the decision variables to maximize profits. Nikunja et al. [21] discussed a two-level supply chain model dominated by a manufacturer that considered the cost of greenhouse gas emissions during the manufacturing process. The Stackelberg game method was used to analyze and compare the profit functions of the decentralized model and the centralized model. Using revenue-sharing contracts and asymmetric Nash bargaining strategies resolve channel conflicts and achieve surplus profit-sharing among channel members. Arpita et al. [22] suggested using integrated game and Stackelberg game methods to study the optimal inventory level, sales price, promotion effort of traditional retail channel, direct online e-retail channel, and dualchannel mode. The conclusion showed that in the integrated system, it was beneficial to all members of the supply chain. Wang et al. [23] considered the Stackelberg game method to study how the fairness concern level of mobile phone manufacturers and operators affected the pricing between unlocking channel and bundling channel in the field of mobile phone supply chain. The results showed that the introduction of fairness may have a significant impact on channel selection decisions. Chen et al. [24] constructed a game tree with incomplete information in rational cryptographic protocol. The sequential equilibrium was used to prove that rational participants had no motivation to deviate from honest behavior, so that rational participants could reconstruct secrets correctly. Dimitrakopoulos et al. [25] used the queuing games to optimize the queuing system and compared the observable and unobservable versions under different information structures. Li et al. [26] got the Nash equilibrium premium strategy of the insurance company with the goal of maximizing the terminal exponential utilities through the dynamic pricing game method and studied the pricing of the insurance contract.

In the supply chain game theory, there have been many game methods in the past, such as the newsboy model, game tree, calculus method, analytical method, Stackelberg game method, Bertrand, Cournot Bertrand, and two-stage game method, but the Bayesian Stackelberg game is rarely used to get the optimal solutions of supply chain members.

2.2. Customer Showrooming Behavior. Different from previous studies about the impact of showrooming degree on decision-making in the dual-channel supply chain, this paper investigates the profit change with or without showrooming in multichannel. Many researchers focused on multichannel and showrooming. For example, Yan et al. [10] proposed introducing the WeChat channel into a traditional online and offline dual-channel supply chain system and compared the profit level of different supply chain channels. They showed that the premise for manufacturers to make profits was that consumers accepted the WeChat channel or were not sensitive to the services of physical stores. Viejferenandez et al. [8] summarized three kinds of shopping methods. The first way was direct online shopping, the second mode called customer showrooming behavior was to collect information offline and purchase online by computers, and the third pattern was to collect information from physical stores but purchase online by mobile phone. They used multiple regression analysis to conclude that free riders using smartphones in stores were more likely to buy products at higher prices. Narasimhan et al. [27] considered the advantages and disadvantages of customers' showrooming behavior in evaluating clothing products, saving money, perceiving enjoyment, and searching costs in the field of clothing. Wang et al. [28] understood the influence of customers' showrooming and webrooming behaviors, and information disclosure decisions on channel members and finally found that for online retailers, customers' webrooming behavior and information nondisclosure were the best choices. Liu et al. [13] established and compared four Stackelberg models in which manufacturers opened online channels and invested in offline services simultaneously model (MM), manufacturers opened online channels, but retailers invested in offline services model (MR), retailers opened online channels, but manufacturers invested in offline services model (RM), and retailers also opened online channels and invested in offline channels model (RR). In the end, they believed that no matter what kind of channel structure, free-riding would generate profits for manufacturers, retailers, and the entire supply chain. Raj et al. [7] studied a manufacturer and two independent retailers: an offline physical store retailer and an online retailer. The manufacturer adopted a unilateral pricing policy (UPP) that mandatory regulated all retailers to adopt the lowest retail prices to encourage retailers to provide better services before customer showrooming. They speculated that under UPP, offline and online retailers were more profitable, and this growth may be at the expense of manufacturers' profits. $\mathrm{Pu}$ et al. [29] studied the effect of customer showrooming behavior on channel pricing and sales effort in a dualchannel supply chain composed of an online manufacturer and an offline retailer. The results showed that the costsharing contract could effectively improve the operational efficiency of the decentralized dual-channel supply chain and bring benefits to both parties. Zhou et al. [30] studied the impact of showrooming on the pricing and profits under the differential pricing and nondifferential pricing model. They found that the retailer was willing to provide a higher service level if the customer's showrooming degree was high and the manufacturer's service cost share was large. Li et al. [6] studied the influence of the showrooming effect on the price and service effort level in three models of no-service, ex-ante, and ex-post service effort in the dual-channel supply chain. The equilibrium results showed that the showrooming effect enabled enterprises to obtain the maximum benefits in the ex-post service effort model. Basak et al. [31] studied the showrooming effect on physical store pricing before online retailers and online retailers pricing before physical stores, respectively, in dual-channel supply chain. They found that you chose whichever model, showrooming not only affected offline stores but also was detrimental to online retailers. The above researchers mainly focus on the impact of the freeriding effect on the profit of different channels' price, service, 
and profits. In addition to the research of customer showrooming behavior, this article also studies the expected profit from the perspective of no customer showrooming behavior, which can more intuitively reflect the impact of showrooming on corporate decision-making.

\subsection{Information Sharing in an Uncertain Demand. The last} stream of this article is to investigate information sharing among channel subjects under the uncertainty of demand caused by forecast errors. Wang et al. [32] studied the information sharing between a contract manufacturer (CM) and an original equipment manufacturer (OEM) in a supply chain and discussed the decisions under endogenous wholesale price and exogenous wholesale price, respectively. They thought that under the exogenous wholesale price, information sharing was more beneficial to OEM, but not to CM. Yue et al. [33] compared the optimal solutions under the make-to-order scenario (MTO) and make-to-stock scenario (MTS) when the retailer and the manufacturer shared the demand forecast information in the traditional retail channel and direct marketing channel. The results showed that the direct marketing channel harmed the retailer's performance but was favorable to the manufacturer and the whole supply chain. Yan [34] addressed information sharing between the franchisor and franchisee by using Bayesian forecasting methodology in high-tech firms and optimized them with a revenue-sharing mechanism. Mishra et al. [35] proposed a two-echelon supply chain with a single manufacturer and a single retailer. They set the price according to the individual uncertain demand forecast and analyzed the incentive of demand forecast sharing. They found that the manufacturer has been profitable all the time, and the retailer could make a profit only when their mutual demand expectation was greater than the manufacturer's forecast. Zhang et al. [36] proposed that two types of customers with different purchasing behaviors were called snobs and conformists who occupied the market in different proportions in the luxury supply chain. The uncertainty of customers' preference for products led to the information uncertainty between the retailer and the manufacturer. They studied price strategy, manufacturer's market target strategy, and manufacturer's and retailer's information policy preference strategy. The results showed that the manufacturer would benefit from no information, private information, or information sharing strategies. Liu et al. [37] explored information sharing in a fresh product e-tailing supply chain consisting of a supplier providing freshness-keeping effort and an e-tailer providing value-added service. Then, they designed an incentive contract with a transfer payment that stimulated the e-tailer to share information with the supplier. They showed that under voluntary information sharing, the e-tailer increased (decreased) both the retail price and service level under high (low) demand information sharing. Lu et al. [38] observed that the information received by manufacturers from retailers may be wrong and studied the value of information sharing in information error. Wang et al. [39] characterized the information sharing problem of manufacturers and retailers in a supply chain using wholesale price contract strategy under the condition of continuous or interrupted market demand. The results showed that when the level of information reliability was lower, information sharing was more beneficial to manufacturers but did harm to retailers and the whole supply chain. Yu et al. [40] investigated a two-stage supply chain model consisting of a risk-neutral retailer and a risk-neutral supplier over a selling season, which studied informationsharing effect on carbon emission reduction. They showed that the supplier prefers information sharing but the retailer preferred noninformation sharing. Demand information sharing did not affect global emission reduction but significantly reduced the "wasted emission." Although numerous researchers have studied information sharing under uncertain demand, most of them focus on inventory, contract coordination incentive mechanism, customer preference, and so on. However, the above researchers have not studied the change of information sharing with or without showrooming, which provides a new understanding of information sharing.

This study uses Bayesian Stackelberg game theory to construct and compare four multichannel supply chain models that combine showrooming and information sharing. Meanwhile, we obtain the optimal solutions for decision variables and the benefits of supply chain members. The research in this paper fills the gaps in the theoretical research on information sharing and showrooming in the current multichannel supply chain. In summary, this research has made contributions from three aspects:

(1) Based on the traditional dual-channel online and offline channel competition, the online competition between the retailer and the manufacturer has been introduced, and the showrooming behavior of customers has become more diversified. In a dualchannel supply chain structure, showrooming will have a negative impact on the supply chain. This paper studies the impact of showrooming on supply chain members under a multichannel supply chain structure. This model makes showrooming a certain contribution to the role of multichannel.

(2) This article compares price competition and expected profit under the condition of uncertain demand. This satisfies the conditions of demand uncertainty in real life and makes new contributions to the supply chain game.

(3) The main contribution of this research lies in the comparison between information sharing and no information sharing and studies whether information sharing can coordinate the customer showrooming behavior. Many papers usually use profit-sharing contracts or cost-sharing contracts to coordinate the supply chain, and few papers analyze the supply chain from a new perspective of information sharing.

In summary, the research results of this article provide a scientific reference value for multichannel supply chain members. It also supplements the original supply chain operation content of showrooming and information sharing. 


\section{Problem Description and Notations}

The paper considers a multichannel apparel supply chain consisting of a single retailer and a single manufacturer, which is illustrated in Figure 1. As the Stackelberg game leader, the manufacturer sets up a direct channel for customers and an indirect channel for the retailer. The retailer, as a subordinate dealer, also establishes online and offline channels for customers, namely, the WeChat channel and traditional brick-and-mortar store channel. Among these three different fashion sales channels above, the retailer's traditional channel exclusively provides high-quality presales services, such as trying some clothes on in physical stores. Customers choose a suitable channel according to different prices and services. If customers compare the three channels and find that the price of the physical store is the lowest, then they buy in the store directly, which shows that customers do not have showrooming behavior. If customers experience the presales service in the physical store and find that the price of the online channel is lower than that of the physical store, they will choose online to buy, which means that customers have showrooming behavior. At the same time, supply chain members pay more attention to the cooperation, because the manufacturer occupies a part of the market, and the retailer decides whether to share information with the manufacturer according to its pricing strategy.

We assume that all channels sell the same kind of products, $\widetilde{D}_{i}^{N}$ are the demand functions of customers without showrooming behavior, and $\widetilde{D}_{i}^{S}$ are the demand functions of customers with showrooming behavior [29], which have been represented by the following equations:

$$
\begin{aligned}
\widetilde{D}_{r f}^{N} & =\widetilde{a}-p_{r f}+b\left(p_{r o}+p_{m o}\right)+s, \\
\widetilde{D}_{r o}^{N} & =\widetilde{a}-p_{r o}+b\left(p_{r f}+p_{m o}\right), \\
\widetilde{D}_{m o}^{N} & =\widetilde{a}-p_{m o}+b\left(p_{r f}+p_{r o}\right),
\end{aligned}
$$

where $\widetilde{D}_{i}^{N}$ are the demand functions of channel $i$ $(i=r f, r o, m o)$ without customer showrooming behavior. The market demand of the physical stores is $\widetilde{a}_{r f}$, the market demand of the WeChat channel is $\tilde{a}_{r o}$, and the market demand of the manufacturer online direct is $\tilde{a}_{m o}$. To maintain analytical tractability, we assume $\tilde{a}_{r f}=\widetilde{a}_{r o}=$ $\widetilde{a}_{m o}=\widetilde{a}$, which is also used by [30]. The market uncertainty demand is represented as $\widetilde{a}=a+\varepsilon, \varepsilon \sim N\left(0, \sigma^{2}\right)$, of which $\widetilde{a}$ is a random variable, $a$ is the market potential deterministic demand, and $\varepsilon$ is the market demand forecast value that is normally distributed with a mean of zero and a variance of $\sigma^{2}$ influenced by all kinds of social factors. $p_{i}$ is the sales price of channel $i \quad(i=r f, r o, m o)$. For example, the rise of manufacturers' direct sales price will harm their direct sales demand, but it will have a positive effect on the demand for rival retailers. The parameter $b(0<b<1)$ is the cross-price elasticity coefficient, which means that the demand sensitivity of a certain commodity to the price changes of other related substitute commodities. $s$ is the service level of the retailer's physical store, which is the vital decision variable besides sales price and wholesale price:

$$
\begin{aligned}
& \widetilde{D}_{r f}^{S}=\widetilde{a}-p_{r f}+b\left(p_{r o}+p_{m o}\right)+(1-\theta) s, \\
& \widetilde{D}_{m o}^{S}=\widetilde{a}-p_{m o}+b\left(p_{r f}+p_{m o}\right)+t \theta s .
\end{aligned}
$$

The parameter $\widetilde{D}_{i}^{S}$ is the demand function of channel $i$ $(i=r f, r o, m o)$ with showrooming. In equation (2), compared with equation (1), online channel demand growth is brought by the retailer's service owing to customer showrooming behavior. $\theta(0<\theta<1)$ is the showrooming coefficient of customers from offline to online channels, which implies that the proportion $\theta$ of customers choose online showrooming in the shopping process. $t(0<t<1)$ is the proportion of the manufacturer's online direct channel to the total online channels, and $1-t$ is the proportion of the retailer's WeChat channel to the total online channels. To improve the readability of our study, the variables and parameters in this paper are shown in Table 1.

The retailer has made great efforts in service, so it has to pay the corresponding service costs. According to $[29,30]$, the service cost is $(1 / 2) k s^{2}$. For the sake of simplicity, we assume that $k=1$, so its cost is $(1 / 2) s^{2}[6,41]$. This paper assumes that the production cost is too small compared with the wholesale price, so the production cost can be ignored on the premise that it would not affect the overall supply chain profits. The profit functions of the retailer and the manufacturer can be expressed as follows:

$$
\begin{aligned}
& \widetilde{\pi}_{r}=\left(p_{r f}-w\right) \widetilde{D}_{r f}+\left(p_{r o}-w\right) \widetilde{D}_{r o}-\frac{1}{2} s^{2}, \\
& \widetilde{\pi}_{m}=w\left(\widetilde{D}_{r f}+\widetilde{D}_{r o}\right)+p_{m o} \widetilde{D}_{m o},
\end{aligned}
$$

where $\tilde{\pi}_{r}$ is the profit of the retailer, including the retailer's physical store profit $\left(p_{r f}-w\right) \widetilde{D}_{r f}-(1 / 2) s^{2}$ and retailer's WeChat profit $\left(p_{r o}-w\right) D_{r o}$. For the manufacturer's profits $\widetilde{\pi}_{m}$, including wholesale profit $w\left(\widetilde{D}_{r f}+\widetilde{D}_{r o}\right)$ and the manufacturer's online direct channel profit $p_{m o} D_{m o}$.

The market demand is stochastic. The manufacturer and the retailer predict the unknown demand according to their own market information. The retailer makes its demand forecast $f_{r}=\tilde{a}+\varepsilon_{r}, \varepsilon_{r} \sim N\left(0, \sigma_{r}^{2}\right)$ according to the basic demand $\widetilde{a}$. The manufacturer makes its demand forecast $f_{m}=\tilde{a}+\varepsilon_{m}, \varepsilon_{m} \sim N\left(0, \sigma_{m}^{2}\right)$ according to the basic demand $\widetilde{a}$. $\varepsilon_{r}$ and $\varepsilon_{m}$ are forecasting errors, which obey the normal distribution with mean value zero and variances $\sigma_{r}^{2}$ and $\sigma_{m}^{2}$, respectively. When the variances $\sigma_{r}^{2}$ and $\sigma_{m}^{2}$ are larger (smaller), it means lower (higher) prediction accuracy. For convenience, we assume that $\varepsilon_{r}$ and $\varepsilon_{m}$ are independent variables, $\operatorname{Cov}\left(\sigma_{m}^{2}, \sigma_{r}^{2}\right)=0[32,34]$. The relevant conditional expectations such as $[32,33,35]$ are shown as follows:

$$
\begin{aligned}
E\left[\frac{\tilde{a}}{f_{m}}\right] & =\left(1-l_{m}\right) a+l_{m} f_{m}, \\
E\left[\frac{\tilde{a}}{f_{r}}\right] & =\left(1-l_{r}\right) a+l_{r} f_{r}, \\
E\left[\frac{\tilde{a}}{f_{m}, f_{r}}\right] & =I a+J f_{m}+K f_{r},
\end{aligned}
$$




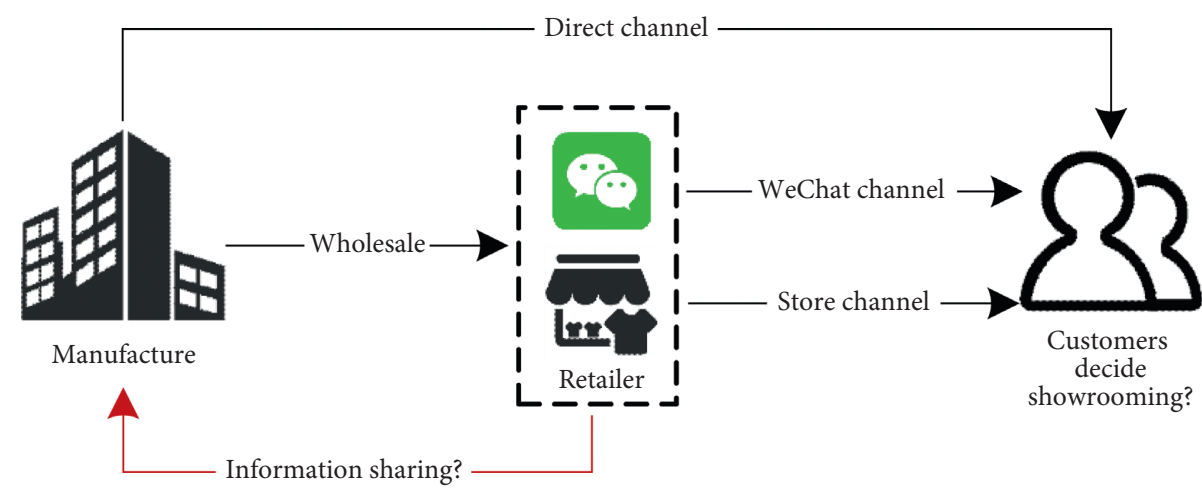

Figure 1: The multichannel in the apparel supply chain.

TABLE 1: Key notations.

\begin{tabular}{lc}
\hline $\begin{array}{l}\text { Notation } \\
i\end{array}$ & Definition \\
$j$ & $j$ represents the channel member, and $j=r, m, s c$ represent retailer, manufacturer, and supply chain, respectively \\
$\widetilde{a}$ & Market uncertainty demand \\
$\varepsilon_{j}$ & Market demand forecast error of member $j$ \\
$\sigma_{j}^{2}$ & The variance of channel member $j$ \\
$b$ & The cross-price elasticity coefficient \\
$p_{i}$ & The sales price of the channel $i$ \\
$\theta$ & Showrooming coefficient of customers \\
$t$ & The proportion of the manufacturer's online direct channel to the total online channels \\
$s$ & The service level of the retailer's physical store \\
$w$ & Wholesale price per unit of product
\end{tabular}

where

$$
\begin{aligned}
& l_{m}=\frac{\sigma^{2}}{\sigma^{2}+\sigma_{m}^{2}}, \\
& l_{r}=\frac{\sigma^{2}}{\sigma^{2}+\sigma_{r}^{2}}, \\
& I=\frac{\sigma_{m}^{2} \sigma_{r}^{2}}{\sigma_{m}^{2} \sigma_{r}^{2}+\sigma^{2}\left(\sigma_{m}^{2}+\sigma_{r}^{2}\right)}, \\
& J=\frac{\sigma_{r}^{2} \sigma^{2}}{\sigma_{m}^{2} \sigma_{r}^{2}+\sigma^{2}\left(\sigma_{m}^{2}+\sigma_{r}^{2}\right)}, \\
& K=\frac{\sigma_{m}^{2} \sigma^{2}}{\sigma_{m}^{2} \sigma_{r}^{2}+\sigma^{2}\left(\sigma_{m}^{2}+\sigma_{r}^{2}\right)} .
\end{aligned}
$$

According to the above formulas, the following conditional expectation functions are deduced, and the proofs are given in Appendix A:

$$
\begin{aligned}
E\left[E\left[\frac{\tilde{a}}{f_{m}, f_{r}}\right]\right] & =E\left[E\left[\frac{\tilde{a}}{f_{m}}\right]\right]=E\left[E\left[\frac{\tilde{a}}{f_{r}}\right]\right]=a, \\
E\left[E^{2}\left[\frac{\tilde{a}}{f_{m}}\right]\right] & =E\left[E\left[\frac{\tilde{a}}{f_{m}}\right] E\left[\frac{\tilde{a}}{f_{m}, f_{r}}\right]\right]=a^{2}+\frac{\sigma^{4}}{\sigma_{m}^{2}+\sigma^{2}} \\
E\left[E^{2}\left[\frac{\tilde{a}}{f_{m}, f_{r}}\right]\right] & =a^{2}+\frac{\sigma^{4}\left(\sigma_{m}^{2}+\sigma_{r}^{2}\right)}{\sigma^{2}\left(\sigma_{m}^{2}+\sigma_{r}^{2}\right)+\sigma_{m}^{2} \sigma_{r}^{2}} .
\end{aligned}
$$

In this paper, the manufacturer is the leader of the Stackelberg game, and the retailer is its follower. Information sharing and customer showrooming behavior will affect their revenues. Therefore, this article studies four different models of showrooming and information sharing:

(1) No information sharing without showrooming (NN)

(2) Information sharing without showrooming (SN)

(3) No information sharing with showrooming (NS)

(4) Information sharing with showrooming (SS)

\section{Analysis of Pricing Equilibrium without Showrooming}

4.1. No Information Sharing (NN). In this section, we focus on the situation without showrooming and information sharing among channels. The manufacturer is the leader of the Stackelberg, and the retailer is its follower. The known information of the retailer is that they can deduce their retail prices from the optimal wholesale prices and online direct selling prices provided by the manufacturer and thus derive the demand $\widetilde{D}_{r}$. The retailer usually has no incentive to share market forecast information with the manufacturer, and therefore, information asymmetry exists between the manufacturer and the retailer. The retailer can know the forecast information $f_{r}$ and $f_{m}$, while the manufacturer only knows its forecast information $f_{m}$, which is similar to [35]. Under the condition of no information sharing, the 
retailer and the manufacturer can optimize their earnings, which are shown as follows:

$$
\begin{aligned}
E\left[\frac{\widetilde{\pi}_{r}^{N}}{f_{m}}, f_{r}\right] & =E\left[\frac{\left(\left(p_{r f}-w\right) \widetilde{D}_{r f}^{N}+\left(p_{r o}-w\right) \widetilde{D}_{r o}^{N}-(1 / 2) s^{2}\right)}{f_{m}}, f_{r}\right], \\
E\left[\frac{\tilde{\pi}_{m}^{N}}{f_{m}}\right] & =E\left[\frac{\left(w\left(\widetilde{D}_{r f}^{N}+\widetilde{D}_{r o}^{N}\right)+p_{m o} \widetilde{D}_{m o}^{N}\right)}{f_{m}}\right] .
\end{aligned}
$$

The order of the game between the manufacturer and the retailer is as follows: (1) the retailer decides whether to share its demand forecast information $f_{r}$ with the manufacturer; (2) the manufacturer first sets the wholesale price and direct sale price; (3) the retailer decides the online and offline price and service level according to the information provided by the manufacturer, as shown in Figure 2. Using the Bayesian Stackelberg game method to solve the problem, we first take the first derivative of $\pi_{r}^{N}$ with respect to $p_{r f}, p_{r o}$, and $s$, and we have

$$
\begin{aligned}
& \frac{\partial E\left[\tilde{\pi}_{r}^{N} / f_{m}, f_{r}\right]}{\partial p_{r f}}=E\left[\frac{\tilde{a}}{f_{m}, f_{r}}\right]-2 p_{r f}+b\left(2 p_{r o}+p_{m o}\right)+(1-b) w+s, \\
& \frac{\partial E\left[\tilde{\pi}_{r}^{N} / f_{m}, f_{r}\right]}{\partial p_{r o}}=E\left[\frac{\tilde{a}}{f_{m}, f_{r}}\right]-2 p_{r o}+b\left(2 p_{r f}+p_{m o}\right)+(1-b) w, \\
& \frac{\partial E\left[\tilde{\pi}_{r}^{N} / f_{m}, f_{r}\right]}{\partial s}=p_{r f}-w-s .
\end{aligned}
$$

Proposition 1. When $b^{2}<(1 / 2)$ (the proofs are given in Appendix B), we can get the unique optimal strategy by setting each first derivative to zero at the same time and get the retailer's optimal response functions as follows:

$$
\begin{aligned}
p_{r f}^{N} & =\frac{(1+b) E\left[\widetilde{a} /\left(f_{m}, f_{r}\right)\right]+b(1+b) p_{m o}-b^{2} w}{1-2 b^{2}}, \\
p_{r o}^{N} & =\frac{(1+2 b) E\left[\widetilde{a} /\left(f_{m}, f_{r}\right)\right]+b(1+2 b) p_{m o}+\left(1-b-2 b^{2}\right) w}{2\left(1-2 b^{2}\right)}, \\
s^{N} & =\frac{(1+b) E\left[\widetilde{a} /\left(f_{m}, f_{r}\right)\right]+b(1+b) p_{m o}+\left(b^{2}-1\right) w}{1-2 b^{2}} .
\end{aligned}
$$

If the retailer decides not to share information with the manufacturer, it means that the manufacturer does not know the retailer's demand forecast $f_{r}$. Therefore, the retailer's product sales price and service level cannot be predicted by the manufacturer are

$$
\begin{aligned}
p_{r f}^{N N} & =\frac{(1+b) E\left[\tilde{a} / f_{m}\right]+b(1+b) p_{m o}-b^{2} w}{1-2 b^{2}}, \\
p_{r o}^{N N} & =\frac{(1+2 b) E\left[\tilde{a} / f_{m}\right]+b(1+2 b) p_{m o}+\left(1-b-2 b^{2}\right) w}{2\left(1-2 b^{2}\right)}, \\
s^{N N} & =\frac{(1+b) E\left[\tilde{a} / f_{m}\right]+b(1+b) p_{m o}+\left(b^{2}-1\right) w}{1-2 b^{2}} .
\end{aligned}
$$




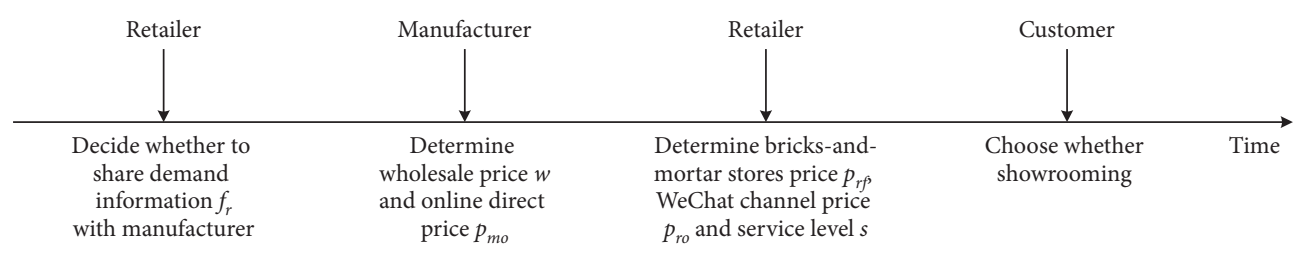

FIGURE 2: The game sequence of the supply chain.

Putting the above solutions (10) into the manufacturer's profit $\pi_{m}^{N}$ (7), then we take the first-order of $\pi_{m}^{N}$ with respect to $w, p_{m o}$, and we have

$$
\begin{gathered}
+\left((2+3 b) p_{m o}+\left(3+b-4 b^{2}\right) w\right) E\left[a / f_{m}\right] \\
E\left[\frac{\tilde{\pi}_{m}^{N N}}{f_{m}}\right]=\frac{\left(7 b^{2}+4 b^{3}-2\right) p_{m o}^{2}-(1-b)^{2}(3+4 b) w^{2}+4 b w p_{m o}\left(1-2 b^{2}\right)}{2\left(1-2 b^{2}\right)}, \\
\frac{\partial E\left[\tilde{\pi}_{m}^{N N} / f_{m}\right]}{\partial w}=\frac{\left(3+b-4 b^{2}\right) E\left[\widetilde{a} / f_{m}\right]+4 b p_{m o}\left(1-2 b^{2}\right)-2 w(3+4 b)(1-b)^{2}}{2\left(1-2 b^{2}\right)}, \\
\frac{\partial E\left[\tilde{\pi}_{m}^{N N} / f_{m}\right]}{\partial p_{m o}}=\frac{(2+3 b) E\left(\tilde{a} / f_{m}\right)-2 p_{m o}\left(2-7 b^{2}-4 b^{3}\right)+4 b w\left(1-2 b^{2}\right)}{2\left(1-2 b^{2}\right)} .
\end{gathered}
$$

Proposition 2. When $0<b<0.45$ (the proofs are given in Appendix B), we can get the unique optimal solutions by setting each first-order to zero simultaneously and then get the manufacturer's optimal wholesale price and online direct price, respectively, as follows:

$$
\begin{aligned}
& w^{N N}=\frac{\left(-6+23 b^{2}+4 b^{3}-16 b^{4}\right) E\left[a / f_{m}\right]}{2\left(-6+10 b+25 b^{2}-35 b^{3}-24 b^{4}+32 b^{5}\right)}, \\
& p_{m o}^{N N}=\frac{\left(-6-5 b+19 b^{2}+8 b^{3}-16 b^{4}\right) E\left[a / f_{m}\right]}{2\left(-6+10 b+25 b^{2}-35 b^{3}-24 b^{4}+32 b^{5}\right)} .
\end{aligned}
$$

$$
\begin{aligned}
& p_{r f}^{N N}=\frac{b\left(6+5 b-14 b^{2}-4 b^{3}+12 b^{4}\right) E\left[\tilde{a} / f_{m}\right]-2\left(-6+4 b+35 b^{2}-10 b^{3}-59 b^{4}+8 b^{5}+32 b^{6}\right) E\left[\tilde{a} / f_{m}, f_{r}\right]}{2\left(1-2 b^{2}\right)\left(6-10 b-25 b^{2}+35 b^{3}+24 b^{4}-32 b^{5}\right)}, \\
& p_{r o}^{N N}=\frac{\left(3-9 b^{2}+5 b^{3}+10 b^{4}-4 b^{5}\right) E\left[\tilde{a} / f_{m}\right]+\left(6+2 b-45 b^{2}-15 b^{3}+94 b^{4}+16 b^{5}-64 b^{6}\right) E\left[\tilde{a} / f_{m}, f_{r}\right]}{2\left(1-2 b^{2}\right)\left(6-10 b-25 b^{2}+35 b^{3}+24 b^{4}-32 b^{5}\right)}, \\
& s^{N N}=\frac{(1+b)\left(\left(-3+6 b+14 b^{2}-19 b^{3}-14 b^{4}+16 b^{5}\right) E\left[\tilde{a} / f_{m}\right]+\left(6-10 b-25 b^{2}+35 b^{3}+24 b^{4}-32 b^{5}\right) E\left[\tilde{a} / f_{m}, f_{r}\right]\right)}{\left(1-2 b^{2}\right)\left(6-10 b-25 b^{2}+35 b^{3}+24 b^{4}-32 b^{5}\right)} .
\end{aligned}
$$


The expected profit of the manufacturer and the retailer is

$$
\begin{aligned}
E\left[\frac{\tilde{\pi}_{r f}^{N N}}{f_{m}, f_{r}}\right] & =\frac{(1+b)\left(\left(-3+6 b+14 b^{2}-19 b^{3}-14 b^{4}+16 b^{5}\right) E\left[\tilde{a} / f_{m}\right]+\left(6-10 b-25 b^{2}+35 b^{3}+24 b^{4}-32 b^{5}\right) E\left[\tilde{a} / f_{m}, f_{r}\right]\right)}{\left(1-2 b^{2}\right)\left(6-10 b-25 b^{2}+35 b^{3}+24 b^{4}-32 b^{5}\right)}, \\
E\left[\frac{\tilde{\pi}_{r o}^{N N}}{f_{m}, f_{r}}\right] & =\frac{(1+2 b)\left(\left(-3+6 b+14 b^{2}-19 b^{3}-14 b^{4}+16 b^{5}\right) E\left[\widetilde{a} / f_{m}\right]+\left(6-10 b-25 b^{2}+35 b^{3}+24 b^{4}-32 b^{5}\right) E\left[\widetilde{a} / f_{m}, f_{r}\right]\right)^{2}}{4\left(1-2 b^{2}\right)\left(6-10 b-25 b^{2}+35 b^{3}+24 b^{4}-32 b^{5}\right)^{2}}, \\
E\left[\frac{\tilde{\pi}_{m}^{N N}}{f_{m}}\right] & =\frac{\left(\left(21-7 b-102 b^{2}-12 b^{3}+80 b^{4}\right) E\left[\widetilde{a} / f_{m}\right]-2\left(3-12 b-37 b^{2}+4 b^{3}+32 b^{4}\right) E\left[\widetilde{a} / f_{m}, f_{r}\right]\right) E\left[\widetilde{a} / f_{m}\right]}{4\left(6-10 b-25 b^{2}+35 b^{3}+24 b^{4}-32 b^{5}\right)}, \\
E\left[\tilde{\pi}_{m}^{N N}\right] & =E\left[E\left[\frac{\tilde{\pi}_{m}^{N N}}{f_{m}}\right]\right], \\
E\left[\tilde{\pi}_{r f}^{N N}\right] & =E\left[E\left[\frac{\tilde{\pi}_{r f}^{N N}}{f_{m}, f_{r}}\right]\right], \\
E\left[\tilde{\pi}_{r o}^{N N}\right] & =E\left[E\left[\frac{\tilde{\pi}_{r o}^{N N}}{f_{m}, f_{r}}\right]\right] .
\end{aligned}
$$

4.2. Information Sharing (SN). Information is shared between the manufacturer and the retailer, so they know mutual demand forecasts $f_{m}$, $f_{r}$, which are shown as follows:

$$
\begin{gathered}
E\left[\frac{\tilde{\pi}_{r}^{S N}}{f_{m}, f_{r}}\right]=E\left[\frac{\left(\left(p_{r f}-w\right) \widetilde{D}_{r f}^{N}+\left(p_{r o}-w\right) \widetilde{D}_{r o}^{N}-(1 / 2) s^{2}\right)}{f_{m}, f_{r}}\right], \\
E\left[\frac{\widetilde{\pi}_{m}^{S N}}{f_{m}, f_{r}}\right]=E\left[\frac{\left((w-c)\left(\widetilde{D}_{r f}^{N}+\widetilde{D}_{r o}^{N}\right)+\left(p_{m o}-c\right) \widetilde{D}_{m o}^{N}\right)}{f_{m}, f_{r}}\right] .
\end{gathered}
$$

If the retailer decides to share the information with the manufacturer, it means that the manufacturer knows the retailer's demand forecast value $f_{r}$. Taking the retailer's optimal response functions (9) into the manufacturer's profit $\widetilde{\pi}_{m}^{S N}(14)$, then we calculate the first-order partial derivative for $w$ and $p_{m o}$, respectively:

$$
\begin{aligned}
E\left[\frac{\tilde{\pi}_{m}^{S N}}{f_{m}, f_{r}}\right] & =\frac{\left(7 b^{2}+4 b^{3}-2\right) p_{m o}^{2}-(1-b)^{2}(3+4 b) w^{2}+4 b w p_{m o}\left(1-2 b^{2}\right)+\left((2+3 b) p_{m o}+\left(3+b-4 b^{2}\right) w\right) E\left[a / f_{m}, f_{r}\right]}{2\left(1-2 b^{2}\right)}, \\
\frac{\partial E\left[\tilde{\pi}_{m}^{S N} / f_{m}\right]}{\partial w} & =\frac{\left(3+b-4 b^{2}\right) E\left[\tilde{a} / f_{m}, f_{r}\right]+4 b p_{m o}\left(1-2 b^{2}\right)-2 w(3+4 b)(1-b)^{2}}{2\left(1-2 b^{2}\right)}, \\
\frac{\partial E\left[\tilde{\pi}_{m}^{S N} / f_{m}\right]}{\partial p_{m o}} & =\frac{(2+3 b) E\left(\tilde{a} / f_{m}, f_{r}\right)-2 p_{m o}\left(2-7 b^{2}-4 b^{3}\right)+4 b w\left(1-2 b^{2}\right)}{2\left(1-2 b^{2}\right)} .
\end{aligned}
$$

Proposition 3. When $0<b<0.45$ (the proofs are given in Appendix $B)$, we can get the unique optimal solutions by setting each first-order to zero simultaneously and then obtain the manufacturer's optimal wholesale price and online direct price: 


$$
\begin{aligned}
& w^{S N}=\frac{\left(-6+23 b^{2}+4 b^{3}-16 b^{4}\right) E\left[a / f_{m}, f_{r}\right]}{2\left(-6+10 b+25 b^{2}-35 b^{3}-24 b^{4}+32 b^{5}\right)}, \\
& p_{m o}^{S N}=\frac{\left(-6-5 b+19 b^{2}+8 b^{3}-16 b^{4}\right) E\left[a / f_{m}, f_{r}\right]}{2\left(-6+10 b+25 b^{2}-35 b^{3}-24 b^{4}+32 b^{5}\right)} .
\end{aligned}
$$

Then, the retailer's optimal solutions can be found by taking these solutions (17) into solutions (9):

$$
p_{r f}^{S N}=\frac{\left(12-2 b-41 b^{2}+2 b^{3}+32 b^{4}\right) E\left[\tilde{a} / f_{m}, f_{r}\right]}{2\left(6-10 b-25 b^{2}+35 b^{3}+24 b^{4}-32 b^{5}\right)},
$$

$$
\begin{aligned}
p_{r o}^{S N} & =\frac{\left(9+2 b-36 b^{2}-6 b^{3}+32 b^{4}\right) E\left[\tilde{a} / f_{m}, f_{r}\right]}{2\left(6-10 b-25 b^{2}+35 b^{3}+24 b^{4}-32 b^{5}\right)}, \\
s^{S N} & =\frac{\left(3-b-9 b^{2}+3 b^{3}+8 b^{4}\right) E\left[\tilde{a} / f_{m}, f_{r}\right]}{6-10 b-25 b^{2}+35 b^{3}+24 b^{4}-32 b^{5}} .
\end{aligned}
$$

Taking equations (17) and (18) into equation (15), the expected payoff of the manufacturer and the retailer is

$$
\begin{aligned}
E\left[\frac{\tilde{\pi}_{r f}^{S N}}{f_{m}, f_{r}}\right] & =\frac{\left((1+b)\left(2+b-2 b^{2}\right)\left(3-4 b-5 b^{2}+8 b^{3}\right)^{2} E^{2}\left[\tilde{a} / f_{m}, f_{r}\right]\right)}{2\left(6-10 b-25 b^{2}+35 b^{3}+24 b^{4}-32 b^{5}\right)^{2}}, \\
E\left[\frac{\tilde{\pi}_{r o}^{S N}}{f_{m}, f_{r}}\right] & =\frac{\left((1+2 b)\left(1-2 b^{2}\right)\left(3-4 b-5 b^{2}+8 b^{3}\right)^{2} E^{2}\left[\tilde{a} / f_{m}, f_{r}\right]\right)}{4\left(6-10 b-25 b^{2}+35 b^{3}+24 b^{4}-32 b^{5}\right)^{2}}, \\
E\left[\frac{\tilde{\pi}_{m}^{S N}}{f_{m}, f_{r}}\right] & =\frac{\left(15+17 b-28 b^{2}-20 b^{3}+16 b^{4}\right) E^{2}\left[\tilde{a} / f_{m}, f_{r}\right]}{4\left(6-10 b-25 b^{2}+35 b^{3}+24 b^{4}-32 b^{5}\right)^{2}}, \\
E\left[\tilde{\pi}_{r f}^{S N}\right] & =E\left[E\left[\frac{\tilde{\pi}_{r}^{S N}}{f_{m}, f_{r}}\right]\right] \\
E\left[\tilde{\pi}_{r o}^{S N}\right] & =E\left[E\left[\frac{\tilde{\pi}_{r}^{S N}}{f_{m}, f_{r}}\right]\right] \\
E\left[\tilde{\pi}_{m}^{S N}\right] & =E\left[E\left[\frac{\tilde{\pi}_{m}^{S N}}{f_{m}, f_{r}}\right]\right] .
\end{aligned}
$$

Proposition 4. In the context of no showrooming, this paper uses the Bayesian Stackelberg equilibrium price and service level strategies to analyze. We compare the wholesale price, sales prices, and service level between information sharing and no information sharing situations under the premise of $f_{r}>E\left[f_{r} / f_{m}\right]$ and $b<0.45:(1) w^{S N}>w^{N N}$; (2) $p_{r f}^{S N}>p_{r f}^{N N}$; (3) $p_{r o}^{S N}>p_{r o}^{N N}$; (4) $p_{m o}^{S N}>p_{m o}^{N N}$; (5) $s^{S N}>s^{N N}$. Proofs of Proposition 4 are given in Appendix $C$.

Proposition 5. Under the premise of $f_{r}>E\left[f_{r} / f_{m}\right]$, (1) $\pi_{m}^{S N}>\pi_{m}^{N N}$ when $b$ satisfies $b<0.45$, (2) $\pi_{r f}^{S N}<\pi_{r f}^{N N}$ and

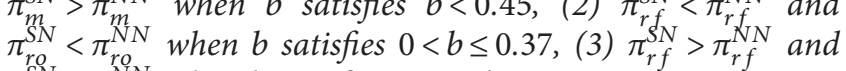
$\pi_{r o}^{S N}>\pi_{r o}^{N N}$ when $b$ satisfies $0.37<b<0.45$.

From Proposition 4, the price with information sharing is higher than that without information sharing, and the service level of the retailer under information sharing is also higher. This is because that channel members need to jointly improve the profits of a single product and weaken the lowprice competition between them in the case of information sharing. From Proposition 5, it can be seen that when the cross price elasticity is satisfied with $b<0.45$, the manufacturer always benefits from information sharing. For the retailer, when the cross price elasticity is satisfied with $0.37<b<0.45$, the retailer's profit is higher with information sharing; when the cross price elasticity is satisfied with $0<b \leq 0.37$, the profit is higher with no information sharing. This shows that the retailer is willing to share information with the manufacturer when there is more competition among channels.

\section{Analysis of Pricing \\ Equilibrium with Showrooming}

5.1. No Information Sharing (NS). The profit functions in the NS model are 


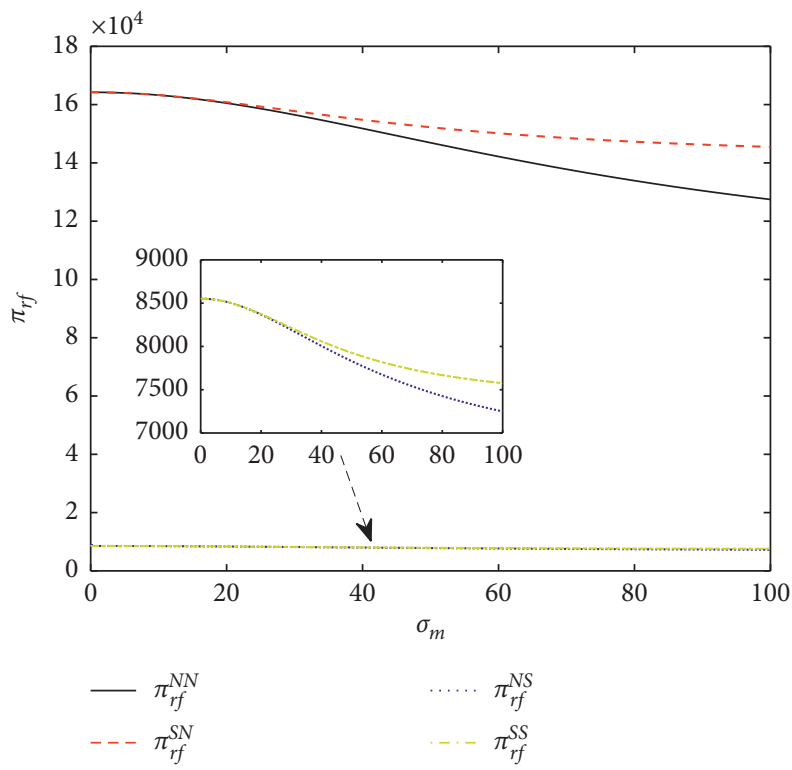

Figure 3: The effect of $\sigma_{m}$ on $\pi_{r f}$.

$$
\begin{aligned}
E\left[\frac{\tilde{\pi}_{r}^{N S}}{f_{m}, f_{r}}\right] & =E\left[\frac{\left(\left(p_{r f}-w\right) \widetilde{D}_{r f}^{S}+\left(p_{r o}-w\right) \widetilde{D}_{r o}^{S}-(1 / 2) s^{2}\right)}{f_{m}, f_{r}}\right], \\
E\left[\frac{\tilde{\pi}_{m}^{N S}}{f_{m}}\right] & =E\left[\frac{\left(w\left(\widetilde{D}_{r f}^{S}+\widetilde{D}_{r o}^{S}\right)+p_{m o} \widetilde{D}_{m o}^{S}\right)}{f_{m}}\right] .
\end{aligned}
$$

The retailer's response functions are

$$
\begin{aligned}
& +b\left[p_{m o}\left(-2+(t-1) \theta+\left(2-3 t+t^{2}\right) \theta^{2}\right)+\theta(t-1)(-3+\theta(2+t)) w\right] \\
p_{r f}^{S}= & \frac{\left(-2(1+b)+(t-1) \theta+(t-1)(t-2) \theta^{2}\right) E\left[\widetilde{a} / f_{m}, f_{r}\right]-2 b^{2}\left(p_{m o}-w\right)+\theta\left(-3-t+\theta\left(2-t-t^{2}\right)\right) w}{\left(-2+4 b^{2}+4 b \theta(1-\theta)(1-t)-4 \theta+2 \theta^{2}\left(t^{2}-2 t+2\right)\right)}, \\
& +b\left[p_{m o}\left(-1+(t-3) \theta+(2-t) \theta^{2}\right)+(1-\theta)(1+\theta(2-3 t)) w\right] \\
p_{r o}^{S}= & \frac{\left((1+2 b)+(3-t) \theta+(t-2) \theta^{2}\right) E\left[\widetilde{a} / f_{m}, f_{r}\right]-2 b^{2}\left(p_{m o}-w\right)+\left(-1-\theta(1+t)+\theta^{2}\left(2-3 t+2 t^{2}\right)\right) w}{\left(-2+4 b^{2}+4 b \theta(1-\theta)(1-t)-4 \theta+2 \theta^{2}\left(t^{2}-2 t+2\right)\right)}, \\
s^{S}= & \frac{(1+b)(\theta t-1)\left(E\left[\tilde{a} / f_{m}, f_{r}\right]-w+b\left(p_{m o}+w\right)\right)}{-1+2 b^{2}+2 b \theta(1-\theta)(1-t)-2 \theta+\theta^{2}\left(t^{2}-2 t+2\right)} .
\end{aligned}
$$

The following calculation process is consistent with the $\mathrm{NN}$ model. Considering that the equilibrium solutions are too complex in showrooming, so we simplify the steps as follows without affecting the results. Because the manufacturer does not know the retailer's forecast value, the retailer's response functions predicted by the manufacturer are $p_{r f}^{N S}, p_{r o}^{N S}$, and $s^{N S}$. When $p_{r f}^{N S}, p_{r o}^{N S}$, and $s^{N S}$ are substituted into $\tilde{\pi}_{m}^{N S}$, we derive the first derivative of $\tilde{\pi}_{m}^{N S}$ with respect to $w$ and $p_{m o}$, and then the manufacturer's optimal wholesale price $w^{N S}$ and sales price $p_{m o}^{N S}$ are calculated. And then we substitute $w^{N S}$ and $p_{m o}^{N S}$ backward to $p_{r f}^{N S}, p_{r o}^{N S}$, and $s^{N S}$, getting the optimal retailer's decision variables. Finally, the above optimal solutions $w^{N S}, p_{m o}^{N S}, p_{r f}^{N S}, p_{r o}^{N S}$, and $s^{N S}$ are all brought into the profit functions $\tilde{\pi}_{r f}^{N S}, \tilde{\pi}_{r o}^{N S}$, and $\tilde{\pi}_{m}^{N S}$ : 


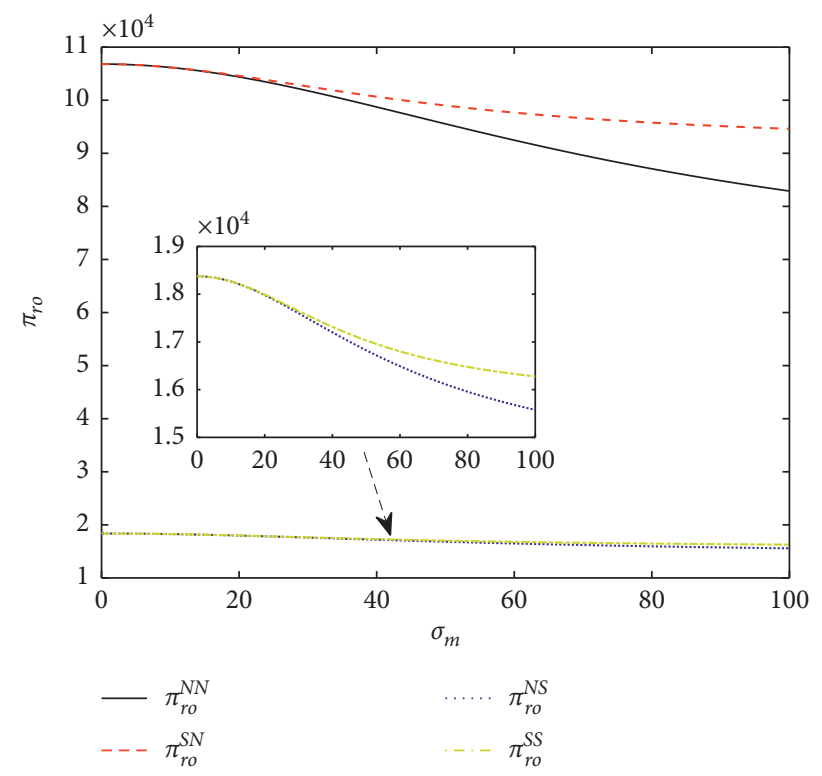

FIgURE 4: The effect of $\sigma_{m}$ on $\pi_{r o}$.

$$
\begin{aligned}
E\left[\frac{\tilde{\pi}_{r f}^{N S}}{f_{m}, f_{r}}\right]= & E\left[p_{r f}^{N S}-w^{N S}\right]\left(E\left[\frac{\tilde{a}}{f_{m}, f_{r}}\right]-E\left[p_{r f}^{N S}\right]+b E\left[p_{r o}^{N S}+p_{m o}^{N S}\right]+(1-\theta) E\left[s_{r}^{N S}\right]\right)-\frac{1}{2} E\left[s^{N S}\right]^{2}, \\
E\left[\frac{\tilde{\pi}_{r o}^{N S}}{f_{m}, f_{r}}\right]= & E\left[p_{r o}^{N S}-w^{N S}\right]\left(E\left[\frac{\tilde{a}}{f_{r}}\right]-E\left[p_{r o}^{N S}\right]+b E\left[p_{r f}^{N S}+p_{m o}^{N S}\right]+(1-t) \theta E\left[s^{N S}\right]\right), \\
E\left[\frac{\tilde{\pi}_{m}^{N S}}{f_{m}}\right]= & E\left[w^{N S}\right]\left(2 E\left[\frac{\tilde{a}}{f_{m}}\right]-E\left[p_{r f}^{N S}+p_{r o}^{N S}\right]+b E\left[p_{r f}^{N S}+p_{r o}^{N S}+2 p_{m o}^{N S}\right]+(1-t) E\left[s^{N S}\right]\right) \\
& +E\left[p_{m o}^{N S}\right]\left(E\left[\frac{\tilde{a}}{f_{m}}\right]-E\left[p_{m o}^{N S}\right]+b E\left[p_{r f}^{N S}+p_{r o}^{N S}\right]+t \theta E\left[s^{N S}\right]\right), \\
E\left[\tilde{\pi}_{r f}^{N S}\right]= & E\left[E\left[\frac{\tilde{\pi}_{r f}^{N S}}{f_{m}, f_{r}}\right]\right], \\
E\left[\tilde{\pi}_{r o}^{N S}\right]= & E\left[E\left[\frac{\tilde{\pi}_{r o}^{N S}}{f_{m}, f_{r}}\right]\right], \\
E\left[\tilde{\pi}_{m}^{N S}\right]= & E\left[E\left[\frac{\tilde{\pi}_{m}^{N S}}{f_{m}}\right]\right] .
\end{aligned}
$$

\subsection{Information Sharing (SS)}

$$
\begin{aligned}
& E\left[\frac{\tilde{\pi}_{r}^{S S}}{f_{m}, f_{r}}\right]=E\left[\frac{\left(\left(p_{r f}-w\right) \widetilde{D}_{r f}^{S}+\left(p_{r o}-w\right) \widetilde{D}_{r o}^{S}-(1 / 2) s^{2}\right)}{f_{m}, f_{r}}\right], \\
& E\left[\frac{\tilde{\pi}_{m}^{S S}}{f_{m}, f_{r}}\right]=E\left[\frac{\left(w\left(\widetilde{D}_{r f}^{S}+\widetilde{D}_{r o}^{S}\right)+p_{m o} \widetilde{D}_{m o}^{S}\right)}{f_{m}, f_{r}}\right] .
\end{aligned}
$$

The profit functions in the SS model are as follows.
The following calculation process is also consistent with the SN model. Considering that the equilibrium solutions are too complex in showrooming, so we simplify the steps as follows without affecting the results. The retailer and the manufacturer know each other's market demand information forecast. Compared with the situation that no information is shared under showrooming, the retailer decides to share their prices with the manufacturer, so $p_{r f}^{S S}, p_{r o}^{S S}$, and $s^{S S}$ are brought into the manufacturers' profit $\tilde{\pi}_{m}^{S S}$. We derive the first derivative of $\tilde{\pi}_{m}^{S S}$ with respect to $w$ and $p_{m o}$ to zero, and the manufacturer's optimal wholesale price $w^{S S}$ and sales price $p_{m o}^{S S}$ are calculated. And then we substitute $w^{S S}$ and $p_{m o}^{S S}$ backward to $p_{r f}^{S S}, p_{r o}^{S S}$, and $s^{S S}$, getting the optimal retailer's 


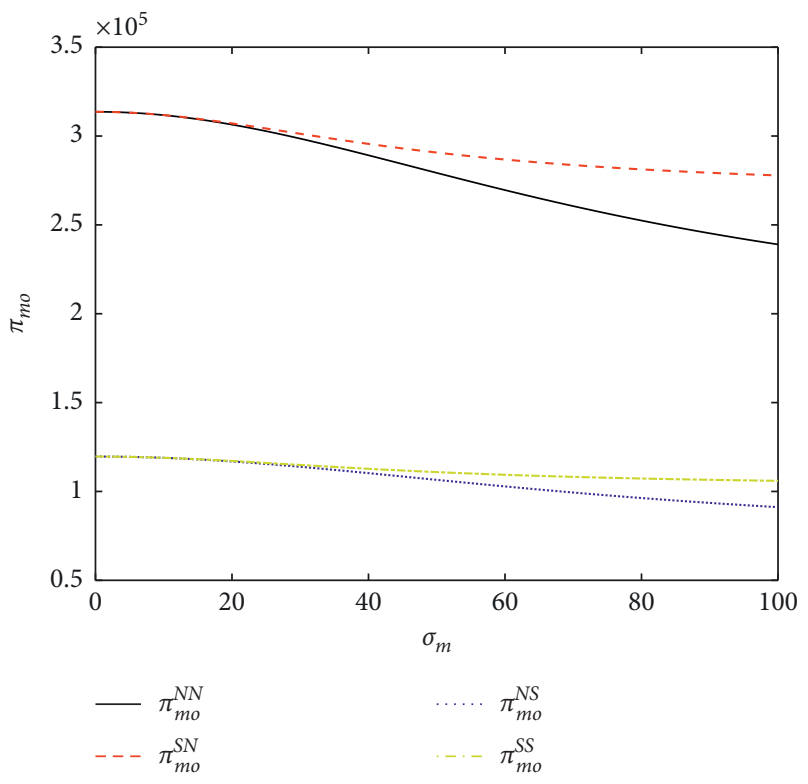

Figure 5: The effect of $\sigma_{m}$ on $\pi_{m o}$.

decision variables. Finally, the above optimal solutions $w^{S S}$, $p_{m o}^{S S}, p_{r f}^{S S}, p_{r o}^{S S}$, and $s^{S S}$ are all brought into the profit functions $\tilde{\pi}_{r f}^{S S}, \tilde{\pi}_{r o}^{S S}$, and $\widetilde{\pi}_{m}^{S S}$ :

$$
\begin{aligned}
E\left[\frac{\tilde{\pi}_{r f}^{S S}}{f_{m}, f_{r}}\right]= & E\left[p_{r f}^{S S}-w^{S S}\right]\left(E\left[\frac{\tilde{a}}{f_{m}, f_{r}}\right]-E\left[p_{r f}^{S S}\right]+b E\left[p_{r o}^{S S}+p_{m o}^{S S}\right]+(1-\theta) E\left[s_{r}^{S S}\right]\right)-\frac{1}{2} E^{2}\left[s^{S S}\right], \\
E\left[\frac{\tilde{\pi}_{r o}^{S S}}{f_{m}, f_{r}}\right]= & E\left[p_{r o}^{S S}-w^{S S}\right]\left(E\left[\frac{\tilde{a}}{f_{r}}\right]-E\left[p_{r o}^{S S}\right]+b E\left[p_{r f}^{S S}+p_{m o}^{S S}\right]+(1-t) \theta E\left[s^{S S}\right]\right), \\
E\left[\frac{\tilde{\pi}_{m}^{S S}}{f_{m}, f_{r}}\right]= & E\left[w^{S S}\right]\left(2 E\left[\frac{\tilde{a}}{f_{m}}\right]-E\left[p_{r f}^{S S}+p_{r o}^{S S}\right]+b E\left[p_{r f}^{S S}+p_{r o}^{S S}+2 p_{m o}^{S S}\right]+(1-t) E[s]\right) \\
& +E\left[p_{m o}^{S S}\right]\left(E\left[\frac{\tilde{a}}{f_{m}}\right]-E\left[p_{m o}^{S S}\right]+b E\left[p_{r f}^{S S}+p_{r o}^{S S}\right]+t \theta E\left[s^{S S}\right]\right), \\
E\left[\tilde{\pi}_{r f}^{S S}\right]= & E\left[E\left[\frac{\tilde{\pi}_{r f}^{S S}}{f_{m}, f_{r}}\right]\right] \\
E\left[\tilde{\pi}_{r o}^{S S}\right]= & E\left[E\left[\frac{\tilde{\pi}_{r o}^{S S}}{f_{m}, f_{r}}\right]\right] \\
E\left[\tilde{\pi}_{m}^{S S}\right]= & E\left[E\left[\frac{\tilde{\pi}_{m}^{S S}}{f_{m}, f_{r}}\right]\right] .
\end{aligned}
$$

\section{Numerical Example Analysis}

We study the effect of information accuracy on the expected profit of the retailer and the manufacturer under different combinations of showrooming and information sharing models. At the same time, we can also compare the profits of three different channels called WeChat online direct stores, retailer physical stores, and manufacturers' online direct 


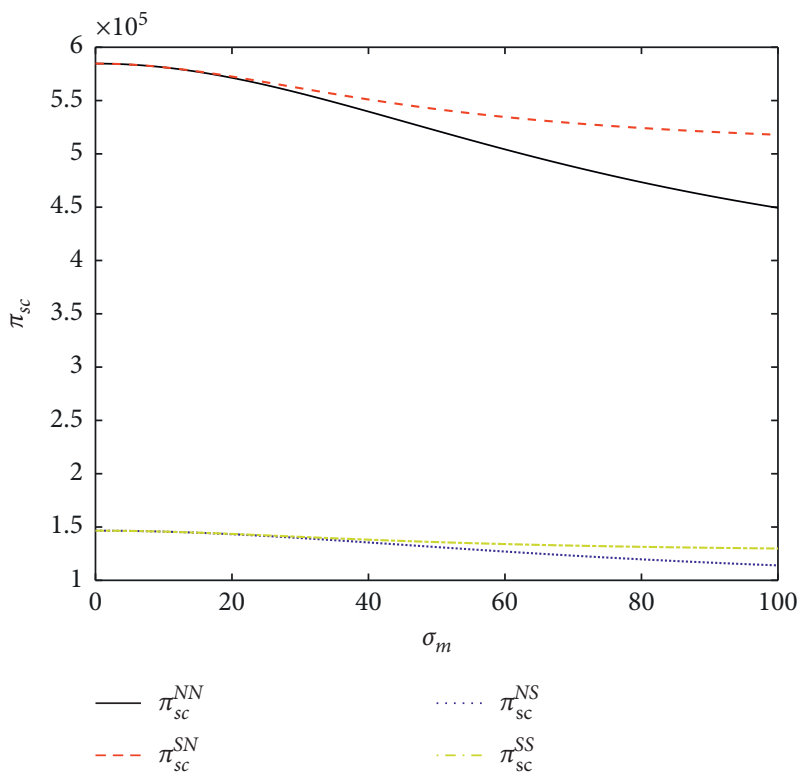

Figure 6: The effect of $\sigma_{m}$ on $\pi_{s c}$.

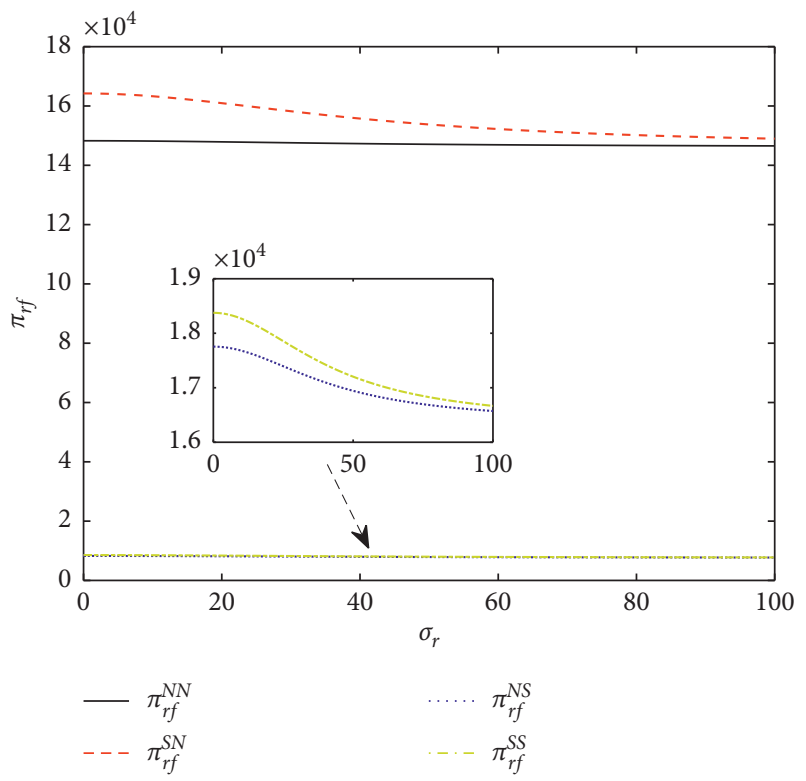

Figure 7: The effect of $\sigma_{r}$ on $\pi_{r f}$.

stores. We use the simulation examples to explain the graph, in which the key parameters are $t=0.4 ; \theta=0.7 ; b=0.43$; and $a=100$. To distinguish different models, graphics are represented by different line shapes and colors.

Figures 3-6 show the impact of the manufacturer's forecast accuracy on the retailer's physical store profit, retailer's WeChat channel profit, manufacturer's direct sales profit, and supply chain profit. We set the relevant parameters as $\sigma=80, \sigma_{r}=60$, and $\sigma_{m} \in\{0,20,40,60,80,100\}$. First of all, with the increase of the standard deviation of the manufacturer's prediction error, but the retailer's profit, the manufacturer's profit, and the supply chain's profit are descending. This is mainly because when the manufacturer's prediction accuracy decreases, it will lead to instability of the subordinate retailer's forecast, thus affecting the profit of each member in the game. Secondly, the profit 


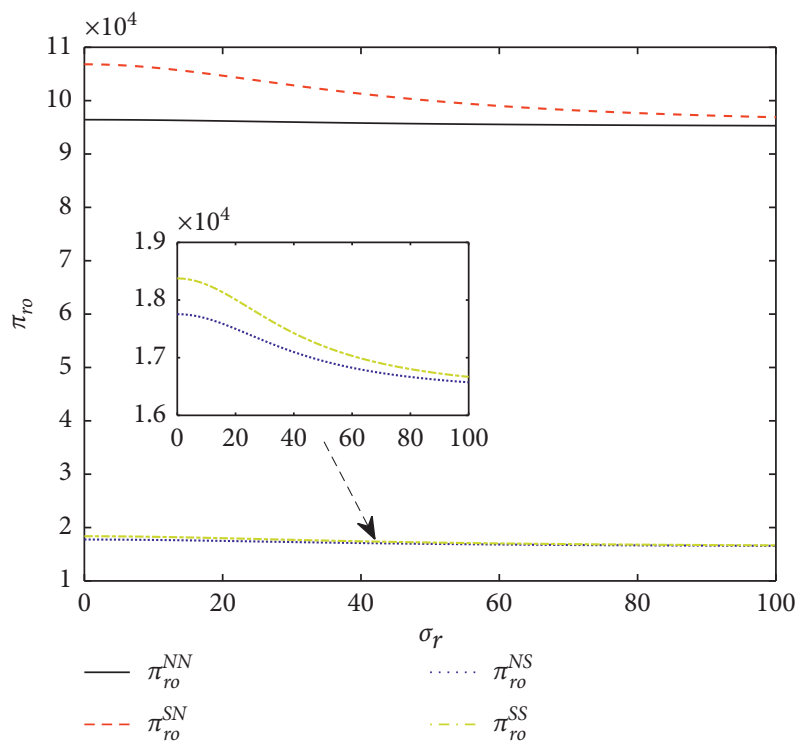

FIgURE 8: The effect of $\sigma_{r}$ on $\pi_{r o}$.

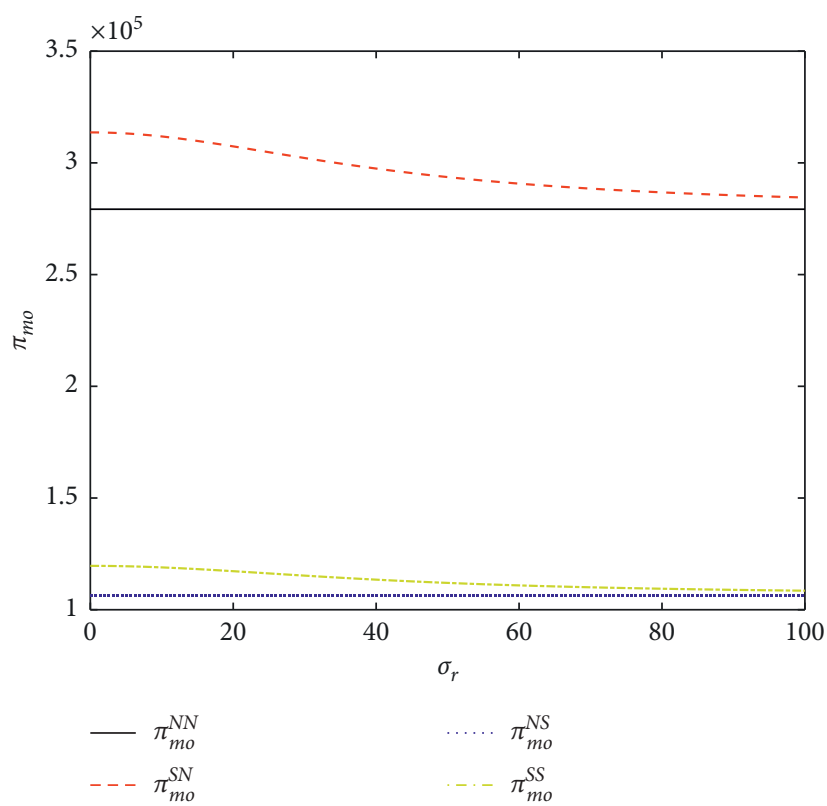

Figure 9: The effect of $\sigma_{r}$ on $\pi_{m o}$.

of customers without showrooming is significantly higher than that of showrooming. This can be explained by the fact that customers have showrooming behavior, which will damage the physical store profit. The physical store pays the service cost but does not gain the revenue, which makes them unwilling to pay more service efforts, so the profit of each channel decreases. The profit under the information sharing model is higher than that without information sharing. This is because when the manufacturer and the retailer cooperate and exchange information with each other, it will be more conducive for channel members to make accurate demand forecasts, which will achieve the 


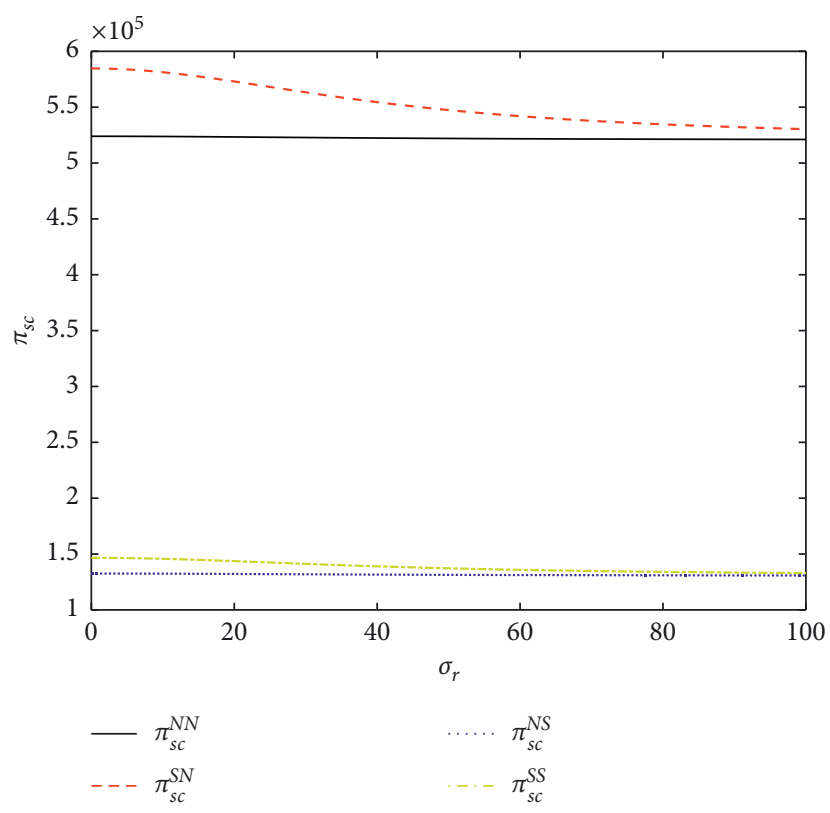

FiguRe 10: The effect of $\sigma_{r}$ on $\pi_{s c}$.

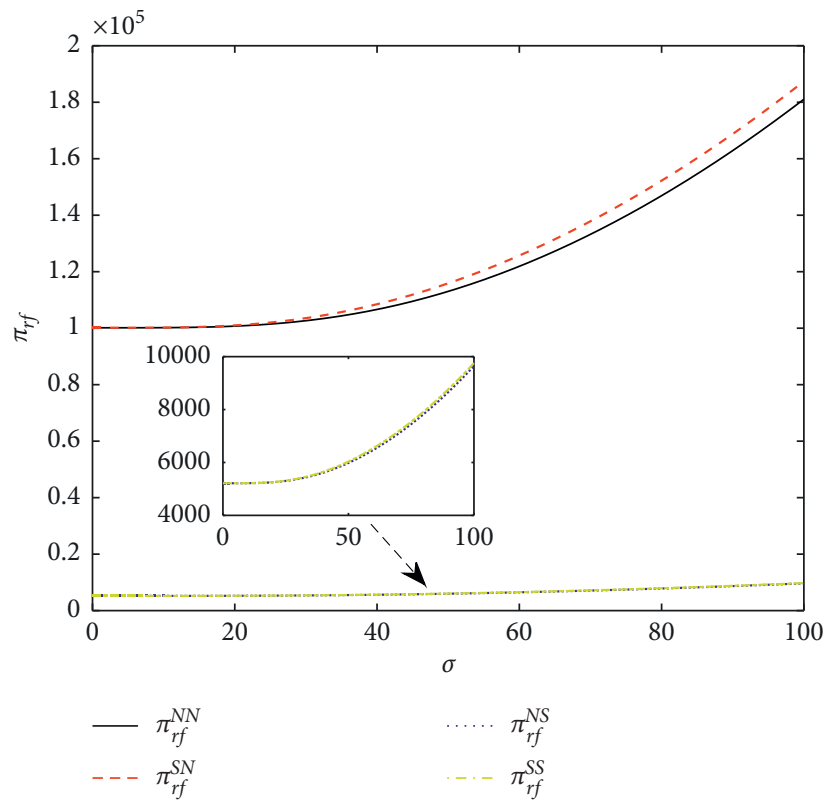

FIgURE 11: The effect of $\sigma$ on $\pi_{r f}$.

goals that reduce inventory and improve profits. Finally, the manufacturer's profit is higher than the retailer's profit. This is explained by the fact that the manufacturer's profits come from online direct marketing profits and the retailer's wholesale profits. At the same time, as the leader of the Stackelberg game, the manufacturer has the initiative right to prioritize the setting of sales prices and wholesale prices. In the case of showrooming, the profits of the manufacturer's direct channel and WeChat channel are higher than that of the retailer's physical store. This is because the showrooming behavior of customers increases the profit of online channels, which is also a big challenge for retailers' physical stores.

Under the assumption of $\sigma=80 ; \sigma_{m}=50$; and $\sigma_{r} \in\{0,20$, $40,60,80,100\}$, Figures $7-10$ reflect the impact of the retailer's forecast accuracy on the profits of each channel. The effect of the retailer's prediction accuracy on profit is very similar to the manufacturer's prediction accuracy on profit; for example, both of them are satisfied $\pi_{i}^{S N}>\pi_{i}^{N N}>$ $\pi_{i}^{S S}>\pi_{i}^{N S}$. However, there are also some differences. Intuitively, the profit under no information sharing without showrooming tends to level off when the retailer's forecast 


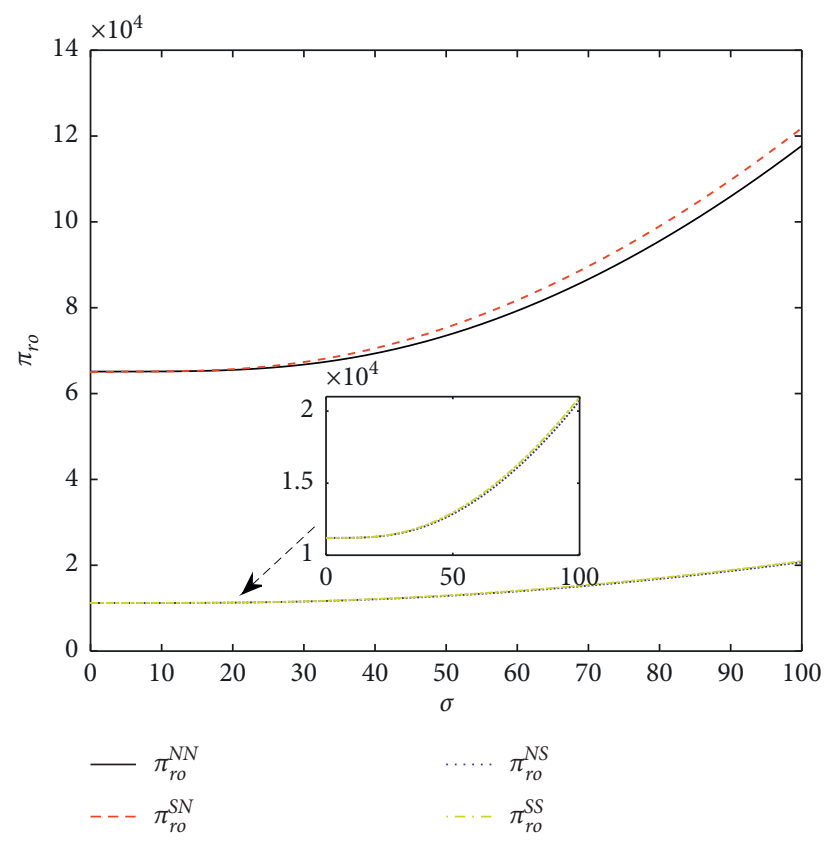

Figure 12: The effect of $\sigma$ on $\pi_{r o}$.

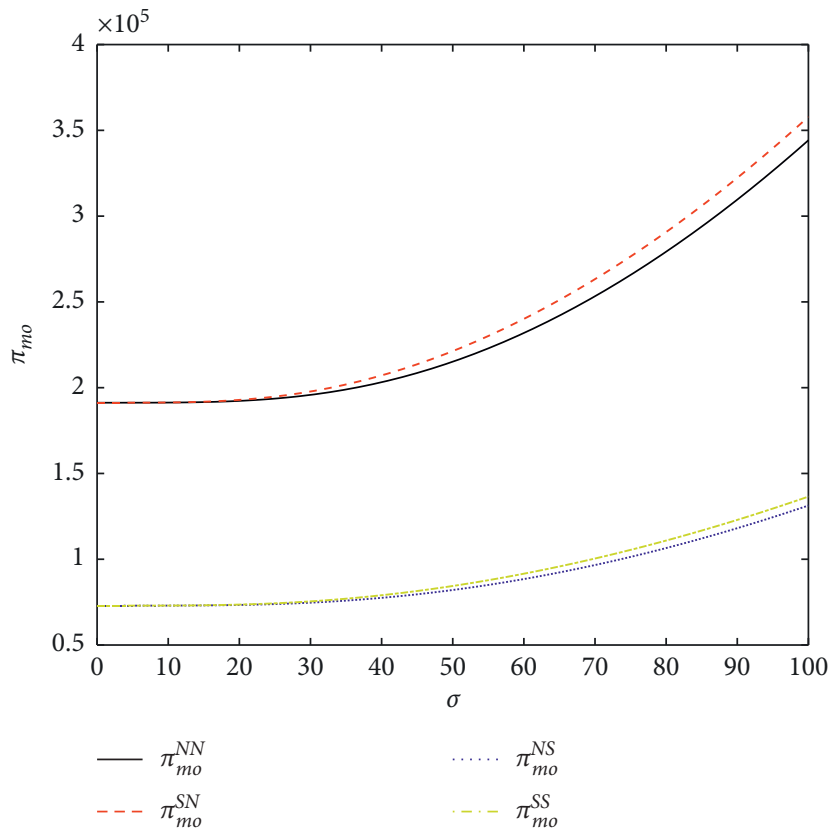

Figure 13: The effect of $\sigma$ on $\pi_{m o}$.

accuracy increases. This result is that the manufacturer does not know the retailer's prediction error before pricing, and the impact on the manufacturer's profit is relatively small when the retailer's forecast changes.

Figures 11-14 more visually reflect the results for the numerical examples, where $\sigma_{r}=60 ; \sigma_{m}=50 ;$ and $\sigma \epsilon$ $\{0,20,40,60,80,100\}$. From the above figures, it can be seen that every channel profit ascends with the $\sigma$ goes up, which means that the greater the market demand forecast error, it is beneficial to both the manufacturer and the retailer. This is contrary to the effect of $\sigma_{m}$ and $\sigma_{r}$ on $\pi_{i}$. On the whole, the profit value of each channel still conforms to $\pi_{i}^{S N}>$ $\pi_{i}^{N N}>\pi_{i}^{S S}>\pi_{i}^{N S}$. The profit under NS and SS models is extremely approximate, which means under the circumstance of the showrooming behavior of customers, the profit has changed very little with $\sigma$ rise whether the 


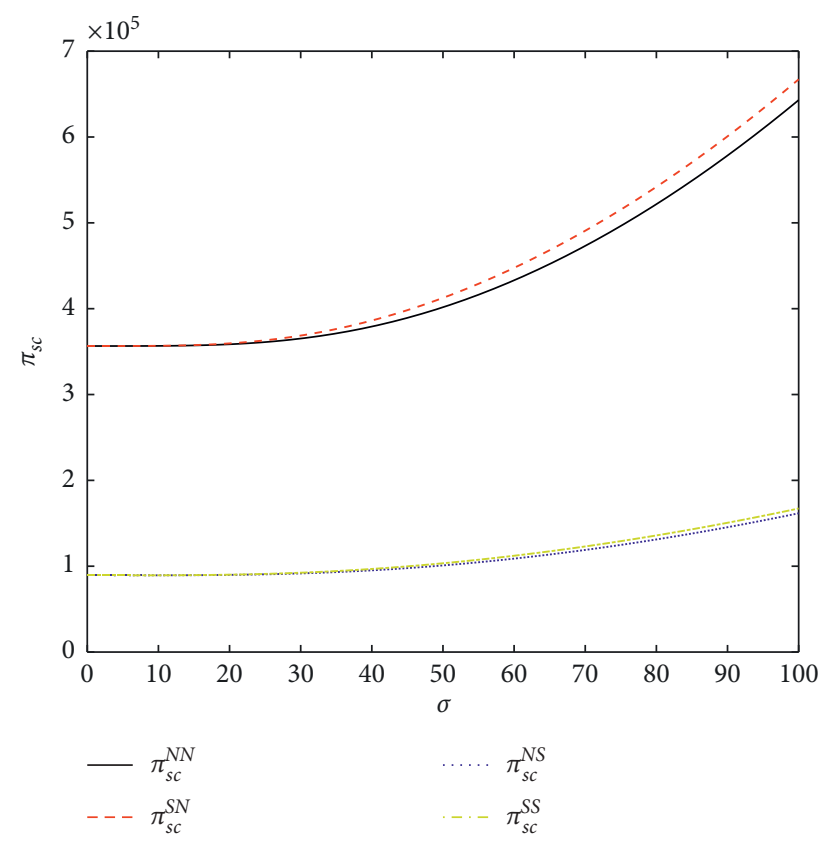

Figure 14: The effect of $\sigma$ on $\pi_{s c}$.

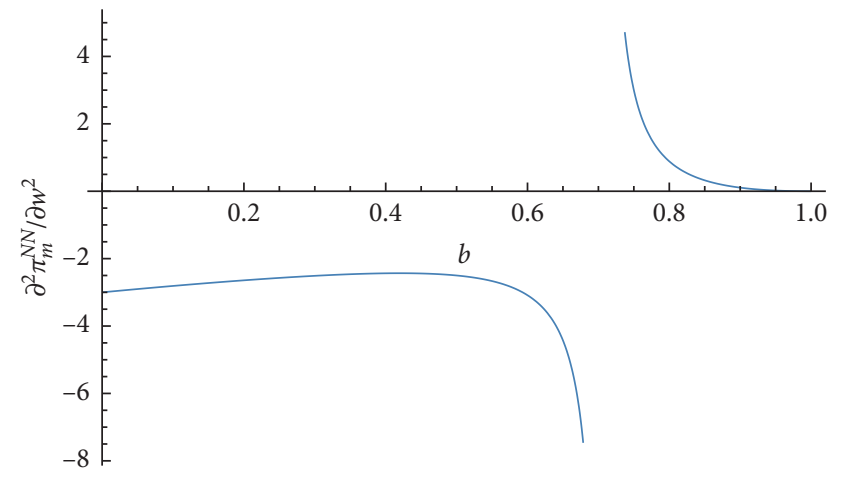

(a)

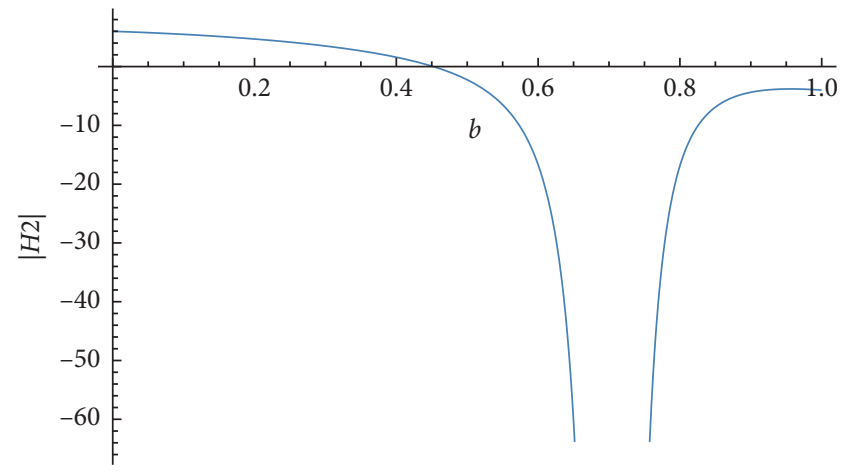

(b)

FiguRE 15: H2 determinant of the Hessian matrix.

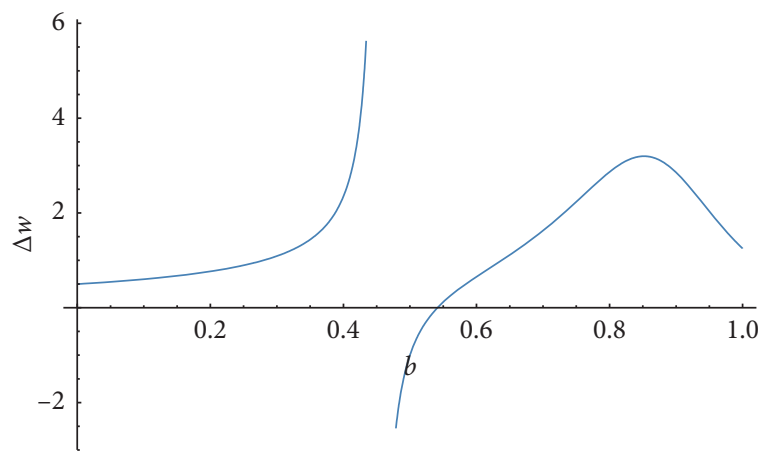

(a)

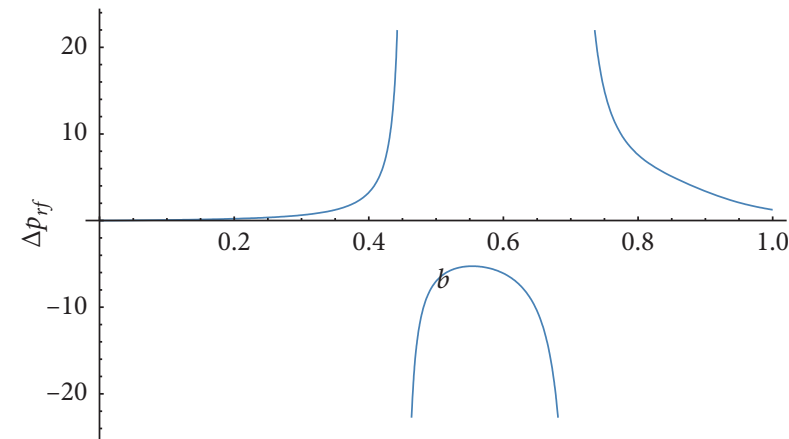

(b)

Figure 16: Continued. 


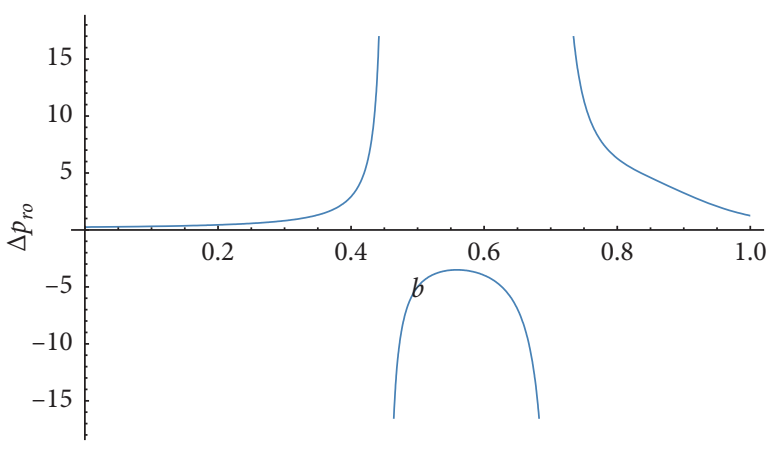

(c)

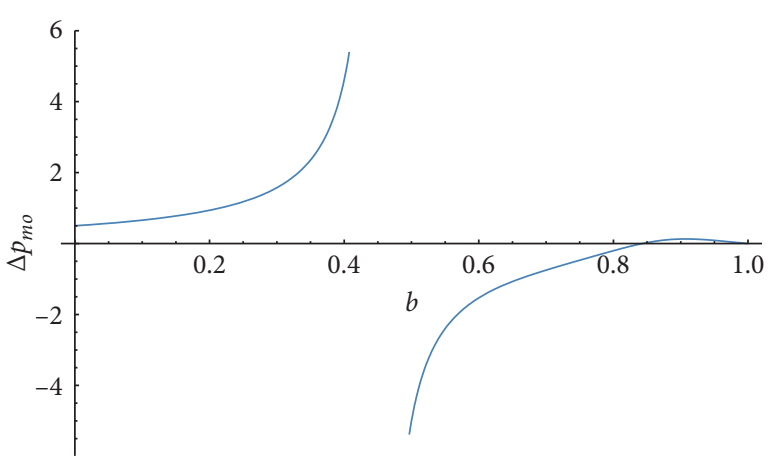

(d)

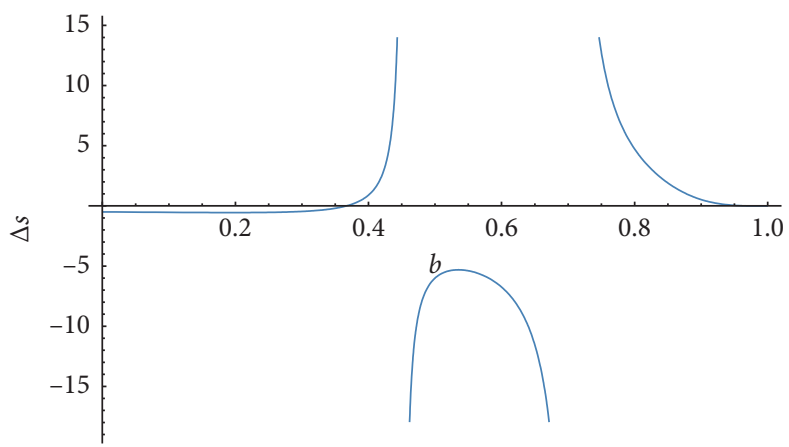

(e)

FIGURE 16: $\Delta w, \Delta p_{r f}, \Delta p_{r o}, \Delta p_{m o}$, and $\Delta s$ with varying $b$.

information is shared or not. This explains that the change of market demand will increase the difficulty of forecasting market demand for the retailer and the manufacturer.

\section{Conclusions}

7.1. Summary. This paper mainly studies the influence of information sharing and customer showrooming on multichannel pricing and service of the supply chain in the apparel industry. We use the Bayesian Stackelberg game method to prove the proposition and make simulation experiments. The results show that in the multichannel apparel supply chain, when the retailer's physical store channel introduces sales efforts, the customer's free-riding tendency will reduce the profits of the retailer and the manufacturer. This is the same as in the dual-channel model, and showrooming will bring negative effects. This shows that adding a new retailer WeChat channel may not solve the problem of customers' free-riding. In the no showrooming model, information sharing is always beneficial to the manufacturer but may damage the interests of the retailer. When the cross-price coefficient is small, that is, the substitutability of the two products is weak, information sharing is beneficial to the supply chain members and the entire supply chain. Channel members can share information to achieve their benefits. According to the numerical analysis, under the influence of prediction accuracy, the profit is the highest in the information sharing without showrooming model, and the profit is the lowest in the no information sharing with showrooming model. The profit of the retailer and the manufacturer increases with the increase of the manufacturer's prediction accuracy, but profit decreases with the increase of market prediction accuracy. In the no information sharing without showrooming model, the profit of each channel changes little with the increase of retailer's prediction accuracy, and the other three model profits increase with the increase of retailer's prediction accuracy.

7.2. Managerial Implications. The research results provide some management implications for managers:

(1) The manufacturer and the retailer can use various forecasting methods to improve forecasting accuracy, which is beneficial to each manager. Managers can achieve the goal of sales forecast timely and accurately. This helps companies to achieve fast response inventory management practices, as information flow is driven by fast forecast results. In the supply chain system, both manufacturing and retail industries will be highly driven by the timely forecast results.

(2) For the superior manufacturers, they should actively encourage the inferior retailers to share information with them. They can establish information sharing contracts and adopt modern information technology such as inventory sharing management software, to maximize their interests and realize supply chain coordination. For retailers, before they decide to share information with manufacturers, they should comprehensively evaluate the impact of various 
factors, because sharing information is not necessarily beneficial to retailers.

(3) The results show that showrooming will bring a negative impact on managers. So, retailers can also try their best to retain customers by improving the sales efforts of physical stores, such as providing advice to customers wearing matching. Manufacturers can also help retailers share part of the cost of sales efforts and make the upstream and downstream enterprises in the supply chain form strategic alliances.

7.3. Limitations and Future Research. There are several limitations in the present study. First of all, the paper only considers the Stackelberg game dominated by the manufacturer and it means the manufacturer has more power than the retailer. However, some retailers such as Wal-Mart and
Tesco lead to the symmetric channel power structure or even the retailer-dominated power structure [42]. Therefore, the subsequent research can consider a more comprehensive channel structure of the distribution of power. Besides, there are also many retailers and manufacturers in real life. For the sake of simplicity, this paper only sets up a single manufacturer with one direct channel and a single retailer with dual-channel to analyze the pricing strategies. Therefore, future research needs to expand our model to satisfy the conditions of $n$ retailers and $n$ manufacturers.

\section{Appendix}

\section{A. Proof of Derivation of Expectation Functions}

$$
\begin{aligned}
& E\left[\varepsilon_{i}^{2}\right]=D\left[\varepsilon_{i}\right]+E^{2}\left[\varepsilon_{i}\right]=D\left[\varepsilon_{i}\right] \\
& E\left(f_{i}\right)=E\left(a+\varepsilon+\varepsilon_{i}\right)=a, \\
& E\left[f_{i}^{2}\right]=E\left[\left(a+\varepsilon+\varepsilon_{i}\right)^{2}\right]=E\left[a^{2}+\varepsilon^{2}+\varepsilon_{i}^{2}+2\left(a \varepsilon+a \varepsilon_{i}+\varepsilon \varepsilon_{i}\right)\right]=E\left[a^{2}+\varepsilon^{2}+\varepsilon_{i}^{2}\right]=a^{2}+\sigma^{2}+\sigma_{i}^{2}, \\
& E\left[f_{m} f_{r}\right]=E\left[\left(a+\varepsilon+\varepsilon_{m}\right)\left(a+\varepsilon+\varepsilon_{r}\right)\right]=E\left[a^{2}+\varepsilon^{2}+a\left(2 \varepsilon+\varepsilon_{m}+\varepsilon_{r}\right)+\varepsilon \varepsilon_{m}+\varepsilon \varepsilon_{r}+\varepsilon_{m} \varepsilon_{r}\right]=a^{2}+\sigma^{2}, \\
& E\left[E\left[\frac{\tilde{a}}{f_{i}}\right]\right]=E\left[\left(1-l_{i}\right) a+l_{i} f_{i}\right]=E\left[\frac{\sigma_{i}^{2}}{\sigma^{2}+\sigma_{i}^{2}} a+\frac{\sigma^{2}}{\sigma^{2}+\sigma_{i}^{2}} f_{i}\right]=\frac{\sigma_{i}^{2}}{\sigma^{2}+\sigma_{i}^{2}} a+\frac{\sigma^{2}}{\sigma^{2}+\sigma_{i}^{2}} E\left[f_{i}\right]=a, \\
& E\left[E\left[\frac{\tilde{a}}{f_{m}, f_{r}}\right]\right]=E\left[I a+J f_{m}+K f_{r}\right]=\frac{\sigma_{m}^{2} \sigma_{r}^{2} a+\sigma_{r}^{2} \sigma^{2} E\left[f_{m}\right]+\sigma_{m}^{2} \sigma^{2} E\left[f_{r}\right]}{\sigma_{m}^{2} \sigma_{r}^{2}+\sigma^{2}\left(\sigma_{m}^{2}+\sigma_{r}^{2}\right)}=a, \\
& E\left[E^{2}\left[\frac{\widetilde{a}}{f_{m}}\right]\right]=E\left[\left(\left(1-l_{m}\right) a+l_{m} f_{m}\right)^{2}\right]=E\left[\left(\left(1-l_{m}\right) a\right)^{2}+\left(l_{m} f_{m}\right)^{2}+2 l_{m}\left(1-l_{m}\right) a f_{m}\right] \\
& =\left(\left(1-l_{m}\right) a\right)^{2}+l_{m}^{2}\left(a^{2}+\sigma^{2}+\sigma_{m}^{2}\right)+2 l_{m}\left(1-l_{m}\right) a^{2}=a^{2}+\frac{\sigma^{4}}{\sigma^{2}+\sigma_{m}^{2}}, \\
& E\left[E\left[\frac{\widetilde{a}}{f_{m}}\right] E\left[\frac{\widetilde{a}}{f_{m}, f_{r}}\right]\right]=E\left[\left(\left(1-l_{m}\right) a+l_{m} f_{m}\right)\left(I a+J f_{m}+K f_{r}\right)\right] \\
& =E\left[(I+J+K) a^{2}+l_{m} J\left(\sigma^{2}+\sigma_{m}^{2}\right)+l_{m} K \sigma^{2}\right]=a^{2}+\frac{\sigma^{4}}{\sigma^{2}+\sigma_{m}^{2}}, \\
& E\left[E^{2}\left[\frac{\tilde{a}}{f_{m}, f_{r}}\right]\right]=E\left[\left(I a+J f_{m}+K f_{r}\right)^{2}\right]=a^{2}+\frac{\sigma^{4}\left(\sigma_{m}^{2}+\sigma_{r}^{2}\right)}{\sigma^{2}\left(\sigma_{m}^{2}+\sigma_{r}^{2}\right)+\sigma_{m}^{2} \sigma_{r}^{2}}
\end{aligned}
$$




\section{B. Proof of Hessian Matrix in Proposition 1, Proposition 2, and Proposition 3}

Proposition B.1. We calculate the Hessian matrix of $\pi_{r}^{N}$ with respect to $p_{r f}, p_{r o}$, and $s$, which is

$$
H 1=\left[\begin{array}{ccc}
\frac{\partial^{2} \pi_{r}^{N}}{\partial p_{r f}^{2}} & \frac{\partial^{2} \pi_{r}^{N}}{\partial p_{r f} \partial p_{r o}} & \frac{\partial^{2} \pi_{r}^{N}}{\partial p_{r f} \partial s} \\
\frac{\partial^{2} \pi_{r}^{N}}{\partial p_{r o} \partial p_{r f}} & \frac{\partial^{2} \pi_{r}^{N}}{\partial p_{r o}^{2}} & \frac{\partial^{2} \pi_{r}^{N}}{\partial p_{r o} \partial s} \\
\frac{\partial^{2} \pi_{r}^{N}}{\partial s \partial p_{r f}} & \frac{\partial^{2} \pi_{r}^{N}}{\partial s \partial p_{r o}} & \frac{\partial^{2} \pi_{r}^{N}}{\partial s^{2}}
\end{array}\right]=\left[\begin{array}{ccc}
-2 & 2 b & 1 \\
2 b & -2 & 0 \\
1 & 0 & -1
\end{array}\right],
$$

in order to satisfy $4\left(1-b^{2}\right)>0,-2\left(1-2 b^{2}\right)<0$, and we have $b^{2}<(1 / 2) . H 1$ is negative definite; thus, the profit of the retailer is jointly concave in $p_{r f}, p_{r o}$, and $s$.

Proposition B.2. Obviously, we get the Hessian matrix of $\pi_{m}^{N}$ with respect to $w$ and $p_{m o}$, which is

$$
H 2=\left[\begin{array}{cc}
\frac{\partial^{2} \pi_{m}^{N N}}{\partial w^{2}} & \frac{\partial^{2} \pi_{m}^{N N}}{\partial w \partial p_{m o}} \\
\frac{\partial^{2} \pi_{m}^{N N}}{\partial p_{m o} \partial w} & \frac{\partial^{2} \pi_{m}^{N N}}{\partial p_{m o}^{2}}
\end{array}\right]=\left[\begin{array}{cc}
\frac{2(b-1)^{2}(3+4 b)}{\left(4 b^{2}-2\right)} & \frac{\left(8 b^{3}-4 b\right)}{\left(4 b^{2}-2\right)} \\
\frac{\left(8 b^{3}-4 b\right)}{\left(4 b^{2}-2\right)} & \frac{2\left(2-7 b^{2}-4 b^{3}\right)}{\left(4 b^{2}-2\right)}
\end{array}\right],
$$

when it is satisfied $0<b<0.45$, as shown in Figure 15, H2 is negative definite, and the strictly concave function $\pi_{m}^{N}$ with respect to $w$ and $p_{m o}$ is obtained.

Proposition B.3. Similar to Proposition 2.

\section{Proof of the Difference Between Information Sharing and Non-information Sharing in Proposition 4}

Proposition C.1.

$$
\begin{aligned}
\Delta \widetilde{w} & =\widetilde{w}^{S N}-\widetilde{w}^{N N}=\frac{\left(E\left[\widetilde{a} / f_{m}\right]-E\left[\widetilde{a} / f_{m}, f_{r}\right]\right)\left(6-23 b^{2}-4 b^{3}+16 b^{4}\right)}{2\left(6-10 b-25 b^{2}+35 b^{3}+24 b^{4}-32 b^{5}\right)}, \\
\Delta \tilde{p}_{r f} & =\widetilde{p}_{r f}^{S N}-\widetilde{p}_{r f}^{N N}=\frac{b\left(E\left[\widetilde{a} / f_{m}\right]-E\left[\widetilde{a} / f_{m}, f_{r}\right]\right)\left(6+5 b-14 b^{2}-4 b^{3}+12 b^{4}\right)}{2\left(1-2 b^{2}\right)\left(6-10 b-25 b^{2}+35 b^{3}+24 b^{4}-32 b^{5}\right)}, \\
\Delta \widetilde{p}_{r o} & =\widetilde{p}_{r o}^{S N}-\widetilde{p}_{r o}^{N N}=\frac{\left(E\left[\widetilde{a} / f_{m}\right]-E\left[\widetilde{a} / f_{m}, f_{r}\right]\right)\left(3-9 b^{2}+5 b^{3}+10 b^{4}-4 b^{5}\right)}{2\left(1-2 b^{2}\right)\left(6-10 b-25 b^{2}+35 b^{3}+24 b^{4}-32 b^{5}\right)}, \\
\Delta \widetilde{p}_{m o} & =\widetilde{p}_{r o}^{S N}-\widetilde{p}_{r o}^{N N}=\frac{\left(E\left[\widetilde{a} / f_{m}\right]-E\left[\widetilde{a} / f_{m}, f_{r}\right]\right)\left(6+5 b-19 b^{2}-8 b^{3}+16 b^{4}\right)}{2\left(6-10 b-25 b^{2}+35 b^{3}+24 b^{4}-32 b^{5}\right)}, \\
\Delta\left[\frac{\tilde{a}}{f_{m}, f_{r}}\right]-E\left[\frac{\tilde{a}}{f_{m}}\right] & =\frac{\sigma^{S N}-\widetilde{s}_{m}^{N N}=\frac{\left(E\left[\widetilde{a} / f_{m}\right]-E\left[\widetilde{a} / f_{m}, f_{r}\right]\right)\left(-3+3 b+20 b^{2}-5 b^{3}-33 b^{4}+2 b^{5}+16 b^{6}\right)}{\left(1-2 b^{2}\right)\left(6-10 b-25 b^{2}+35 b^{3}+24 b^{4}-32 b^{5}\right)},}{\left(\sigma^{2}+\sigma_{m}^{2}\right)\left(\sigma_{r}^{2} \sigma_{m}^{2}+\sigma^{2}\left(\sigma_{r}^{2}+\sigma_{m}^{2}\right)\right)}>0,
\end{aligned}
$$


then deduced as $-f_{m} \sigma^{2}-a \sigma_{m}^{2}+f_{r}\left(\sigma^{2}+\sigma_{m}^{2}\right)>0 \Leftrightarrow f_{r}>E$ $\left[f_{r} / f_{m}\right]$.

If the conditions $E\left[\tilde{a} / f_{m}, f_{r}\right]>E\left[\tilde{a} / f_{m}\right]$ are satisfied, the variation of parameters with $b$ is shown in Figure 16.

\section{Data Availability}

The data that support the findings of this paper mainly come from other articles and can be obtained from the corresponding author upon request.

\section{Conflicts of Interest}

The authors declare that they have no conflicts of interest.

\section{References}

[1] K. Behrooz, S. Hamed, S. Soheil, and S. E. Mir Mehdi, "Revenue management in a multi-level multi-channel supply chain considering pricing, greening, and advertising decisions," Journal of Retailing and Consumer Services, vol. 59, 2020.

[2] T. Yi, M. Junhai, X. Lei, K. Timo, and S. Veikko, "Coordination and control of multi-channel supply chain driven by consumers' channel preference and sales effort," Chaos, Solitons \& Fractals, vol. 132, Article ID 109576, 2020.

[3] A. Barman, R. Das, and D. Kanti, "Optimal pricing and greening decision in a manufacturer retailer dual-channel supply chain," Materials Today: Proceedings, 2021.

[4] P. He, Y. He, and H. Xu, "Buy-online-and-deliver-from-store strategy for a dual-channel supply chain considering retailer's location advantage," Transportation Research Part E: Logistics and Transportation Review, vol. 144, Article ID 102127, 2020.

[5] R. Arpita, S. Shib, and C. Kripasindhu, "Optimal pricing of competing retailers under uncertain demand-a two layer supply chain model," Annals of Operations Research, vol. 260, no. 1-2, 2018.

[6] G. Li, L. Li, J. Sun et al., "Pricing and service effort strategy in a dual-channel supply chain with showrooming effect," Transportation Research Part E: Logistics and Transportation Review, vol. 126, pp. 32-48, 2019.

[7] S. P. Raj, B.-D. Rhee, K. Sivakumar et al., "Manufacturer adoption of a unilateral pricing policy in a multi-channel setting to combat customer showrooming," Journal of Business Research, vol. 110, pp. 104-118, 2020.

[8] N. Viejo-Fernandez, M. J. Sanzo-Perez, R. Vazquez-Casielles et al., "Is showrooming really so terrible? start understanding showroomers," Journal of Retailing and Consumer Services, vol. 54, Article ID 102048, 2020.

[9] X. Wen, T.-M. Choi, S.-H. Chung et al., "Fashion retail supply chain management: a review of operational models," International Journal of Production Economics, vol. 207, pp. 34-55, 2019.

[10] B. Yan, Z. Jin, S. Liu et al., "Analyzing a mixed supply chain with a WeChat channel," Electronic Commerce Research and Applications, vol. 29, pp. 90-101, 2018.

[11] Z. Pi, W. Fang, B. Zhang et al., "Service and pricing strategies with competition and cooperation in a dual-channel supply chain with demand disruption," Computers \& Industrial Engineering, 2019.

[12] T. Zhao, X. Xu, Y. Chen et al., "Coordination of a fashion supply chain with demand disruptions," Transportation
Research Part E-logistics and Transportation Review, vol. 134, Article ID 101838, 2020.

[13] L. Liu, L. Feng, B. Xu et al., "Operation strategies for an omnichannel supply chain: who is better off taking on the online channel and offline service?" Electronic Commerce Research and Applications, vol. 39, no. 8, Article ID 100918, 2020.

[14] F. Ye, L. Zhang, Y. Li et al., "Strategic choice of sales channel and business model for the hotel supply chain," Journal of Retailing, vol. 94, no. 1, pp. 33-44, 2017.

[15] S. Shib, "Price competition between green and non green products under corporate social responsible firm," Journal of Retailing and Consumer Services, vol. 55, 2020.

[16] S. Shib, "A structural mathematical model on two echelon supply chain system," Annals of Operations Research, 2021.

[17] S. Shib, "Optimal production lot size and reorder point of a two-stage supply chain while random demand is sensitive with sales teams' initiatives," International Journal of Systems Science, vol. 47, no. 2, 2016.

[18] M. Nikunja, M. Nilkanta, P. Shibaji, and S. Shib, "Analyzing structure of two-echelon closed-loop supply chain for pricing, quality and recycling management," Journal of Cleaner Production, vol. 171, pp. 512-528, 2018.

[19] I. E. Nielsen, S. Majumder, S. Sankar Sana, and S. Saha, "Comparative analysis of government incentives and game structures on single and two-period green supply chain," Journal of Cleaner Production, vol. 235, pp. 1371-1398, 2019.

[20] B. Moumita and S. Shib, "A mathematical model on ecofriendly manufacturing system under probabilistic demand," RAIRO-Operations Research, vol. 53, no. 5, 2019.

[21] M. Nikunja, K. Debabrata, P. Shibaji, and S. Shib, "Managing green house gas emission cost and pricing policies in a twoechelon supply chain," CIRP Journal of Manufacturing Science and Technology, vol. 20, pp. 1-11, 2018.

[22] R. Arpita, S. Shib, and C. Kripasindhu, "Joint decision on EOQ and pricing strategy of a dual channel of mixed retail and e-tail comprising of single manufacturer and retailer under stochastic demand," Computers \& Industrial Engineering, vol. 102, pp. 423-434, 2016.

[23] N. Wang, Z. Fan, and X. Chen, "Effect of fairness on channel choice of the mobile phone supply chain," International Transactions in Operational Research, vol. 28, no. 4, 2019.

[24] Z. Chen, Y. Tian, and C. Peng, "An incentive-compatible rational secret sharing scheme using blockchain and smart contract," Science China Information Sciences, vol. 64, no. 10, 2021.

[25] Y. Dimitrakopoulos, A. Economou, and S. Leonardos, "Strategic customer behavior in a queueing system with alternating information structure," European Journal of Operational Research, vol. 291, no. 3, 2021.

[26] D. Li, B. Li, and Y. Shen, "A dynamic pricing game for general insurance market," Journal of Computational and Applied Mathematics, vol. 389, Article ID 113349, 2020.

[27] R. Narasimhan, V. Pankaj, and K. Kishore, "Investigating consumers' path to showrooming: a perceived value-based perspective," International Journal of Retail \& Distribution Management, vol. 49, no. 2, 2020.

[28] Z. Wang, L. Ran, and D. Yang, "Interplay between quality disclosure and cross-channel free riding," Electronic Commerce Research and Applications, vol. 45, Article ID 101024, 2021.

[29] X. Pu, L. Gong, X. Han et al., "Consumer free riding: coordinating sales effort in a dual-channel supply chain," Electronic Commerce Research and Applications, vol. 22, pp. 1-12, 2017. 
[30] Y.-W. Zhou, J. Guo, W. Zhou et al., "Pricing/service strategies for a dual-channel supply chain with free riding and servicecost sharing," International Journal of Production Economics, vol. 196, pp. 198-210, 2018.

[31] S. Basak, P. Basu, B. Avittathur, and S. Sikdar, "A game theoretic analysis of multichannel retail in the context of "showrooming"” Decision Support Systems, vol. 103, pp. 34-45, 2017.

[32] J. Wang, J. Dong, X. Yue et al., "Information sharing in a supply chain with a coopetitive contract manufacturer," IEEE Transactions on Systems, Man, and Cybernetics, vol. 50, no. 5, pp. 1777-1793, 2018.

[33] X. Yue and J. Liu, "Demand forecast sharing in a dual-channel supply chain," European Journal of Operational Research, vol. 174, no. 1, pp. 646-667, 2006.

[34] R. Yan and K.-Y. Wang, "Franchisor-franchisee supply chain cooperation: sharing of demand forecast information in hightech industries," Industrial Marketing Management, vol. 41, no. 7, pp. 1164-1173, 2012.

[35] B. K. Mishra, S. Raghunathan, X. Yue et al., "Information sharing in supply chains: incentives for information distortion," IIE Transactions, vol. 39, no. 9, pp. 863-877, 2007.

[36] Q. Zhang, J. Chen, G. Zaccour et al., "Market targeting and information sharing with social influences in a luxury supply chain," Transportation Research Part E-logistics and Transportation Review, vol. 133, 2020.

[37] M. Liu, B. Dan, S. Zhang, S. Ma et al., "Information sharing in an e-tailing supply chain for fresh produce with freshnesskeeping effort and value-added service," European Journal of Operational Research, vol. 290, no. 2, pp. 572-584, 2021.

[38] J. Lu, G. Feng, S. Stephen et al., "On the value of information sharing in the presence of information errors," European Journal of Operational Research, 2021.

[39] J.-C. Wang, Y.-Y. Wang, T. Che et al., "Information sharing and the impact of shutdown policy in a supply chain with market disruption risk in the social media era," Information \& Management, vol. 56, no. 2, pp. 280-293, 2019.

[40] Y. Yu, S. Zhou, and Y. Shi, "Information sharing or not across the supply chain: the role of carbon emission reduction," Transportation Research Part E: Logistics and Transportation Review, vol. 137, 2020.

[41] R. He, Y. Xiong, Z. Lin et al., "Carbon emissions in a dual channel closed loop supply chain: the impact of consumer free riding behavior," Journal of Cleaner Production, vol. 134, pp. 384-394, 2016.

[42] J. Gao, H. Han, L. Hou, and H. Wang, "Pricing and effort decisions in a closed-loop supply chain under different channel power structures," Journal of Cleaner Production, vol. 112, no. 112, pp. 2043-2057, 2016. 